\title{
Exceedance of design actions in epicentral areas: insights from the ShakeMap envelopes for the 2016-2017 central Italy sequence
}

\author{
lunio lervolino ${ }^{1}$ (D) Pasquale Cito $^{1}$ - Chiara Felicetta ${ }^{2} \cdot$ Giovanni Lanzano $^{2}$. \\ Antonio Vitale ${ }^{1}$
}

Received: 12 March 2021 / Accepted: 27 July 2021 / Published online: 3 August 2021

(C) The Author(s) 2021

\begin{abstract}
ShakeMap is the tool to evaluate the ground motion effect of earthquakes in vast areas. It is useful to delimit the zones where the shaking is expected to have been most significant, for civil defense rapid response. From the earthquake engineering point of view, it can be used to infer the seismic actions on the built environment to calibrate vulnerability models or to define the reconstruction policies based on observed damage vs shaking. In the case of long-lasting seismic sequences, it can be useful to develop ShakeMap envelopes, that is, maps of the largest ground intensity among those from the ShakeMap of (selected) events of a seismic sequence, to delimit areas where the effects of the whole sequence have been of structural engineering relevance. This study introduces ShakeMap envelopes and discusses them for the central Italy 2016-2017 seismic sequence. The specific goals of the study are: (i) to compare the envelopes and the ShakeMap of the main events of the sequence to make the case for sequence-based maps; (ii) to quantify the exceedance of design seismic actions based on the envelopes; (iii) to make envelopes available for further studies and the reconstruction planning; (iv) to gather insights on the (repeated) exceedance of design seismic actions at some sites. Results, which include considerations of uncertainty in ShakeMap, show that the sequence caused exceedance of design hazard in thousands of square kilometers. The most relevant effects of the sequence are, as expected, due to the mainshock, yet seismic actions larger than those enforced by the code for structural design are found also around the epicenters of the smaller magnitude events. At some locations, the succession of ground-shaking that has excited structures, provides insights on structural damage accumulation that has likely taken place; something that is not accounted for explicitly in modern seismic design. The envelopes developed are available as supplemental material.
\end{abstract}

Keywords Ground motion · Seismic hazard · Earthquake reconstruction policy

Iunio Iervolino

iunio.iervolino@unina.it

1 Dipartimento di Strutture per l'Ingegneria e l'Architettura, Università degli Studi di Napoli Federico II, Naples, Italy

2 Istituto Nazionale di Geofisica e Vulcanologia, sezione di Milano, Milan, Italy 


\section{Introduction}

In Italy, ShakeMap (Wald et al. 1999) is primarily used for emergency management. The shaking intensity is evaluated automatically in near-real-time after the national seismic monitoring network has recorded an earthquake of magnitude equal to or larger than three; moreover, when manually processed and quality-checked waveforms are available, ground motion intensities from ShakeMap are revised. In turn, this information is used to assess the potential relevance of the event for civil defense purposes. Eventually, ShakeMap is also used to relate the observed damage to the built environment, thus providing an estimated measure of ground motion at the construction site. For example, to derive information about the vulnerability of the damaged structures (e.g., Buratti et al. 2017). Furthermore, exceedance of some ground motion thresholds at a site is used in the context of restoration/reconstruction governmental policy; see, for example, the Italian law 122 of 2012, according to which, the need for safety verification and retrofitting in the area hit by the earthquake is also based on the sustained shaking from ShakeMap and the observed/inferred performance of the building.

ShakeMap is earthquake-specific; however, in the case of seismic sequences featuring multiple events with a damaging potential, it may be useful to derive envelopes to delimit the areas with the largest shaking. A striking example is the 2016-2017 central Italy sequence, which started in August 2016 with an earthquake with moment magnitude (M) equal to 6.0. The sequence featured a M6.5 earthquake at the end of October 2016 and let record about fifteen thousand M2+events up to August 2019. Herein, the envelopes are intended as maps where the intensity values are the maxima among multiple ShakeMap for some events, and they have been developed considering the nine M5+earthquakes of the sequence, in terms of peak ground acceleration or PGA, and 5\% damped spectral pseudo-acceleration, $S a(T)$, for $T=\{0.3 \mathrm{~s}, 1 \mathrm{~s}, 3 \mathrm{~s}\}$ The envelopes are compared to the ShakeMap obtained for the M6.5 and M6.0 events. Moreover, the areas in which the exceedance of code-mandated seismic actions used for structural design of ordinary constructions are delimited based on the envelopes. To this aim, design actions for damage control and life safety limit-states, according to the current Italian building code (C.S.LL.PP. 2018), are considered. Finally, it is well known that building codes do not contemplate explicitly damage accumulation, if not qualitatively in the definition of some performance objectives (for example, the definition of the collapse prevention limit state in the Italian code prescribes that following the earthquake [...] the construction still retains a safety margin against vertical actions and a small safety margin towards the collapse due to horizontal actions). To gather some insights about the potential for damage accumulation during the sequence, for some selected locations in the area hit by the considered sequence, the history of intensity each location has experienced is also presented.

The remainder of this paper is structured such that the main features of the 2016-2017 central Italy seismic sequence are presented in brief, first. Second, the ShakeMap made available by the Istituto Nazionale di Geofisica e Vulcanologia (INGV) are introduced. Subsequently, the envelopes are presented and compared to the ShakeMap for the two largest magnitude events also in terms of area of exceedance of code-mandated seismic intensity. Then, exceedance area is quantified for each of the M5+events of the sequence, also considering ShakeMap uncertainty. Finally, for four locations in the area, the intensity breakdown of the sequence is discussed. Some final remarks close the study. 


\section{The 2016-2017 seismic sequence in brief}

Since the end of August 2016, an extended region of central Italy has experienced a longlasting seismic sequence. The initiating event was the Amatrice earthquake that occurred on August 24th, 2016. It was characterized by M6.0 and heavily damaged the villages of Amatrice and Accumoli. This earthquake initiated the sequence abruptly (i.e., no foreshocks are attributed to it) and caused about three-hundred fatalities, resulting from the collapse of several buildings in the area closest to the source. During the coming months, and until January 2017, eight additional seismic M5.0+ events occurred in the area (Luzi et al. 2017). The largest magnitude earthquake of the sequence (M6.5), struck on October 30th, with the epicenter located in the vicinity of the town of Norcia; this event will be hereafter identified as the mainshock. The sequence continued into 2017, with four more events, with magnitude between 5.0 and 5.4, occurring on the same day, January 18th, in the area between the villages of Amatrice and Pizzoli. In fact, seismologists believe the sequence is still not ended as of July 2021.

In Fig. 1, the sequence is represented in terms of number of earthquakes, with magnitude equal to or larger than two, in cells areas $5 \mathrm{~km}$ by $5 \mathrm{~km}$ wide. The displayed earthquakes are those within fifty kilometers from the epicenter of the M6.0 earthquake initiating the sequence. The figure also contains the cumulative number of earthquakes in the selected area, from the beginning of the sequence up to August 2019.

During the 2016-2017 sequence, many villages were near the source of different seismic events of moderate-to-large magnitude, sustaining considerable damage, especially to constructions built according to obsolete seismic standards or without any seismic design at all. What is more, several settlements were found in this near-source situation more than once. In those cases, the extent of the damage suffered by the building stock was, at least partly, attributable to the cumulative effect of being subjected to repeated strong motion shocks and the peculiar features of shaking close to the seismic rupture (e.g., Iervolino et al. 2019a).

This long-duration seismic sequence came in the wake of the 2009 L'Aquila earthquake (e.g., Chioccarelli and Iervolino 2010) and the 2012 Emilia sequence (e.g., Iervolino et al. 2012) to rekindle scientific debate on, among other topics, the seismic actions considered for structural design. Nevertheless, from a scientific point of view, this sequence is unique in the Italian history of instrumental seismicity so far. This is because of the number of moderate-to-large magnitude earthquakes recorded in a relatively short time, and the acquisition of about fifteen thousand recorded ground motions also by temporary accelerometric networks that were deployed as the sequence unfolded. This allowed to develop accurate ShakeMap for many events of the sequence, as discussed in the following sections.

\section{M5+Envelopes and event maps}

INGV has implemented the ShakeMap (v.4.0) tool, developed by the U.S. Geological Survey Earthquake Hazards Program, to produce maps of (horizontal) PGA, peak ground velocity, and spectral acceleration at $0.3 \mathrm{~s}, 1.0 \mathrm{~s}$ and $3.0 \mathrm{~s}$, and macroseismic intensity (i.e., the Mercalli-Cancani-Sieberg scale); see Michelini et al. (2019). ShakeMap estimates ground motion intensity on a regular latitude-longitude points grid, using actual observations, estimates according to ground motion prediction equations and large-scale 

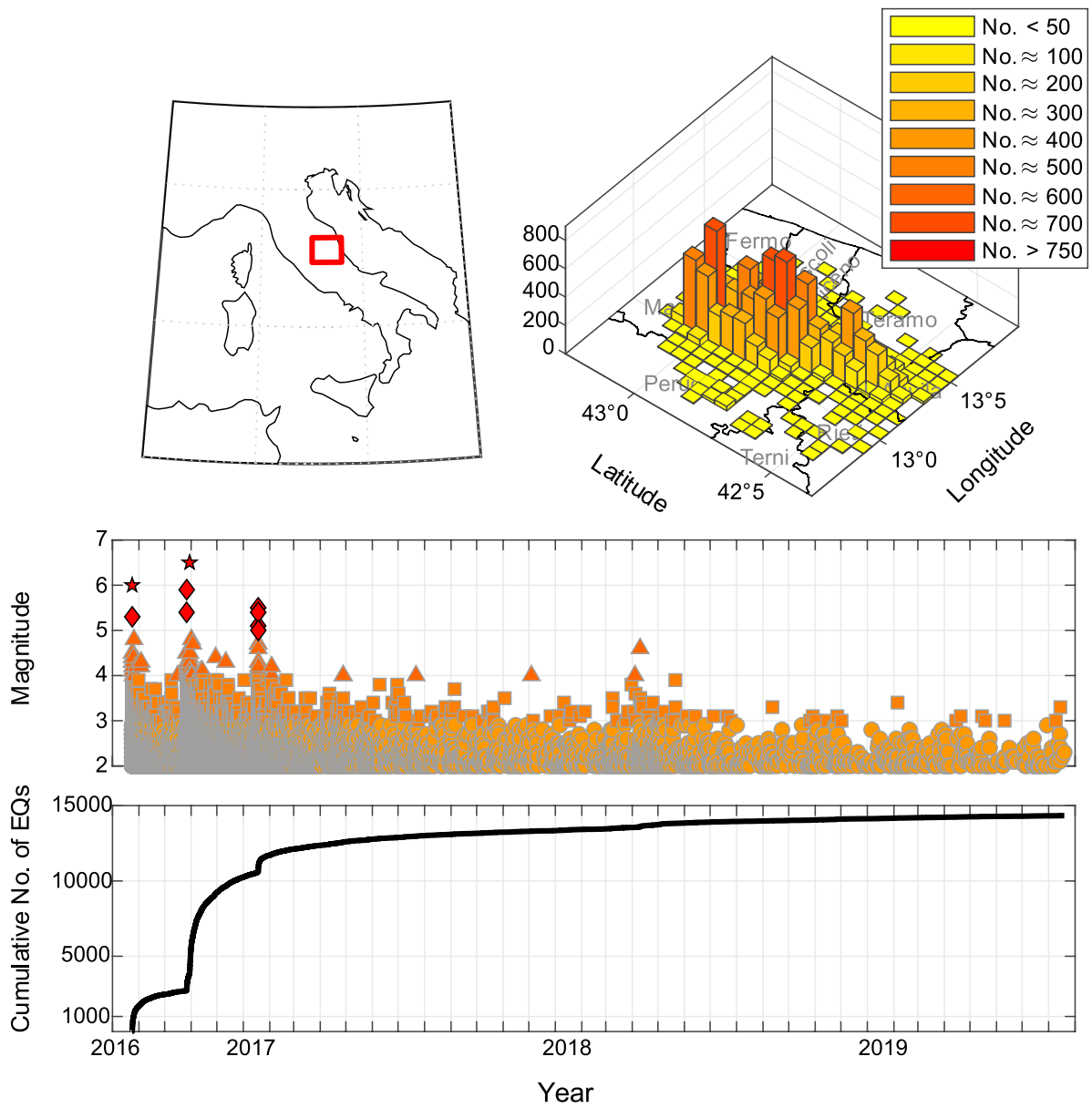

Fig. 1 Number of earthquakes (EQs) with $M \geq 2$ recorded in $5 \mathrm{~km}$ by $5 \mathrm{~km}$ cells during the Aug. 2016Aug. 2019 period within fifty kilometers from the epicenter of the M6.0 event initiating the sequence on Aug. 24th 2016. Data from http://cnt.rm.ingv.it/, last accessed Aug. 2019

information about the local geology; i.e., the average S-wave velocity in the uppermost $30 \mathrm{~m}$. A ShakeMap is produced for any event of magnitude equal to or larger than three and made available publicly (see Data Availability and Material); these data are used to produce the results presented in the following.

ShakeMap envelopes, defined as the maps of maximum ground motion intensity for each site from the various ShakeMap for events pertaining to the same seismic sequence, can serve for identifying the area, at a regional scale, which was most affected by a series of events concentrated in space and time. From the structural perspective, this information may be useful in identifying and/or quantifying the fraction of the building heritage subjected to seismic actions of engineering relevance during a sequence. In this section some ShakeMap envelopes for the central Italy seismic sequence are introduced and compared to two earthquake-specific maps referring to the largest events of the sequence. The study focuses on the Italian region squared in Fig. 2 (left), which covers an inland area about $62,000 \mathrm{~km}^{2}$ wide. It is expanded in Fig. 2 (right), where the seismic stations recording the 

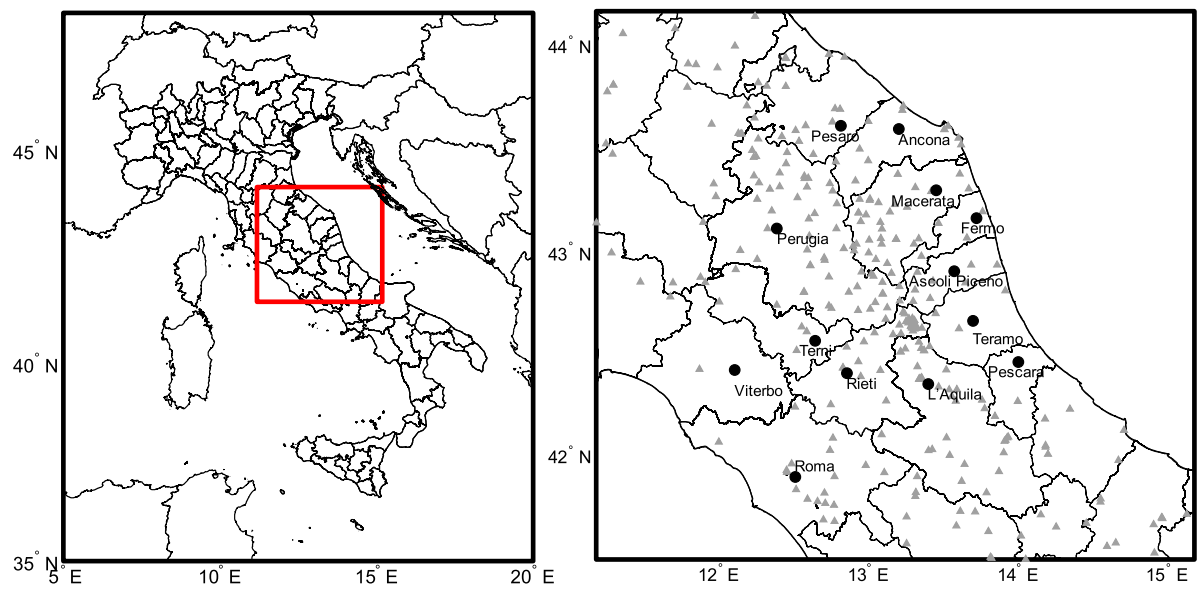

Fig. 2 Left: considered area with respect to Italy. Right: seismic stations in the considered area (triangles) and province capitals (dots) and boundaries (lines)

Fig. 3 Position of the epicenters of the M5+earthquakes of the sequence with respect to Accumoli, Amatrice, Norcia and Visso

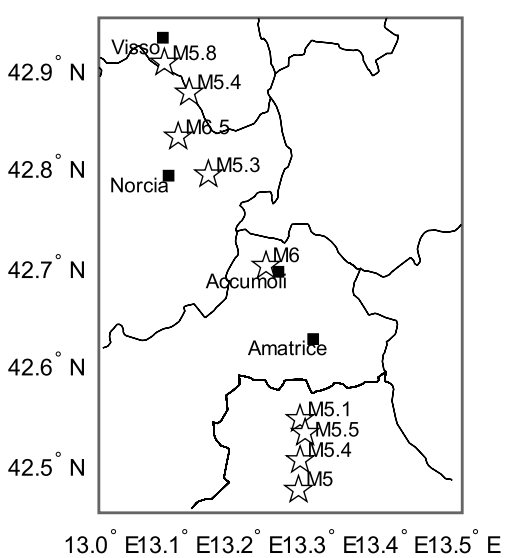

data used to derive the ShakeMap used herein are also reported. The sequence has been quite densely monitored also because a substantial amount of temporary seismic monitoring networks was deployed during the long period it has lasted (e.g., Moretti et al. 2016). In fact, it is important to underline that the quality of ShakeMap, that is, how much it is informative about a seismic event, strictly depends on the number and quality of recordings it is based on; for example, near-source effects such as directivity, may cause spatial variability of ground motions that, being not generally modelled by ground motion prediction equations, need to be captured by a sufficiently dense monitoring network. It has also to be mentioned that ShakeMap assigns at each point of the grid an uncertainty quantification (see Worden et al., 2018, for details) for the provided ground motion estimate, which is discussed in Sects. 5 and 6.

The envelopes herein discussed were computed accounting for the nine earthquakes of the sequence with magnitude larger (or equal) than five occurred so far. Figure 3 provides the epicenters of these M5+ events (black contoured stars) as well as four sites that will be more thoroughly investigated in the following: Accumoli, Amatrice, Norcia, and Visso 
(black squares). In fact, Accumoli was less than $2 \mathrm{~km}$ from the epicenter of the first event of the sequence (M6.0), which occurred on August 24th 2016 at 1:36:32 UTC. In the same day, at 2:33:29 UTC, the second $M>5$ earthquake (i.e., M5.3) occurred at about $4 \mathrm{~km}$ from Norcia. On October 26th at 17:10:36 UTC, the village of Visso was affected by a M5.4 earthquake with epicenter $7 \mathrm{~km}$ distant from the site and a slightly closer event, M5.8, occurred about two hours later. The epicenter of the most severe event (M6.5), which occurred on October 30th at 06:40:18 UTC, was located at less than $5 \mathrm{~km}$ from Norcia and about $10 \mathrm{~km}$ from Visso. Finally, the town of Amatrice was close to the remaining four M5+events, with magnitude between 5.0 and 5.5, which occurred on January 18th 2017 between 9:25:42 and 13:33:37 UTC, each with a distance from the site ranging from 10 to $17 \mathrm{~km}$. All the events had comparable hypocentral depth, being in the 8-10 km range.

ShakeMap for the different events are compiled based on point grids that are different both in extension and points' location. Thus, to compute the envelopes, the shaking values for each of the nine M5+ events were interpolated on a common grid, which is the one of the mainshock ShakeMap, that is, the largest one. The envelopes and the ShakeMap for the M6.0 and M6.5 events are given in Fig. 4, in terms of four spectral ground motion intensity measures. In particular, the figure shows twelve maps; those on the first, second, third and fourth row refer to PGA, $S a(T=0.3 \mathrm{~s}), S a(T=1 \mathrm{~s})$ and $S a(T=3 \mathrm{~s})$, respectively. For a given ground motion intensity measure, the figure shows, from left to right, the ShakeMap envelope of the M5+ earthquakes, that for the M6.0 event and finally that for the mainshock. It can be preliminarily observed that white colored areas are found in each map; they refer to sites subjected to an acceleration lower than $2.5 \%$ of the maximum estimated intensity during the sequence (i.e., the value at the top of the color bar in the figure), that is, $0.018 \mathrm{~g}, 0.037 \mathrm{~g}, 0.022 \mathrm{~g}$ and $0.003 \mathrm{~g}$ for PGA, $S a(T=0.3 \mathrm{~s}), S a(T=1 \mathrm{~s})$ and $S a(T=3 \mathrm{~s})$, respectively, according to ShakeMap. These thresholds are arbitrarily considered as limits of the ShakeMap extension.

Considering a given spectral ordinate, one can note that ShakeMap extension tends to increase with the increasing magnitude, as expected. More quantitatively, with reference to PGA, an acceleration larger than $0.018 \mathrm{~g}$ was estimated in an area covering about 16,900 $\mathrm{km}^{2}$ in the case of M6.0 and 22,500 $\mathrm{km}^{2}$ for M6.5. For both the earthquakes, these areas are almost equal for $S a(T=0.3 \mathrm{~s})$. Indeed, looking at Fig. 4 , it is found that the pattern of the ShakeMap for $S a(T=0.3 \mathrm{~s})$ does not have significative differences with respect to PGA. With reference to $S a(T=1 \mathrm{~s})$, the M6.0 and M6.5 events caused accelerations larger than $0.022 \mathrm{~g}$ in an area equal to approximatively $15,200 \mathrm{~km}^{2}$ and $21,400 \mathrm{~km}^{2}$, respectively. In the case of $S a(T=3 \mathrm{~s})$, the non-white area extends for about $37,000 \mathrm{~km}^{2}$ for M6.0 and $54,000 \mathrm{~km}^{2}$ for the mainshock.

The analysis of the envelopes reveals that large (estimated) ground-shaking intensities are distributed along the northwest-southeast direction (for insights, see Luzi et al. 2017). Herein, it is highlighted that, due to the nine M5+earthquakes, spectral accelerations larger than half of the maximum recorded during the sequence are estimated in an area which overall extends for about $900 \mathrm{~km}^{2}$ in the case of PGA and $S a(T=0.3 \mathrm{~s})$, whereas it is between 400 and $500 \mathrm{~km}^{2}$ for both $S a(T=1 \mathrm{~s})$ and $S a(T=3 \mathrm{~s})$. According to the maps in the left column of Fig. 4, such an area includes the orange-to-red colored sites that were exposed to ground motion intensities larger than about $0.326 \mathrm{~g}, 0.665 \mathrm{~g}, 0.389 \mathrm{~g}$ and $0.06 \mathrm{~g}$ in the case of PGA, $S a(T=0.3 \mathrm{~s}), S a(T=1 \mathrm{~s})$ and $S a(T=3 \mathrm{~s})$, respectively. Envelopes also show that, among the others, the villages of Accumoli, Amatrice, Norcia and Visso, which were seriously damaged by the two M6.0 and M6.5 close-by earthquakes occurred 

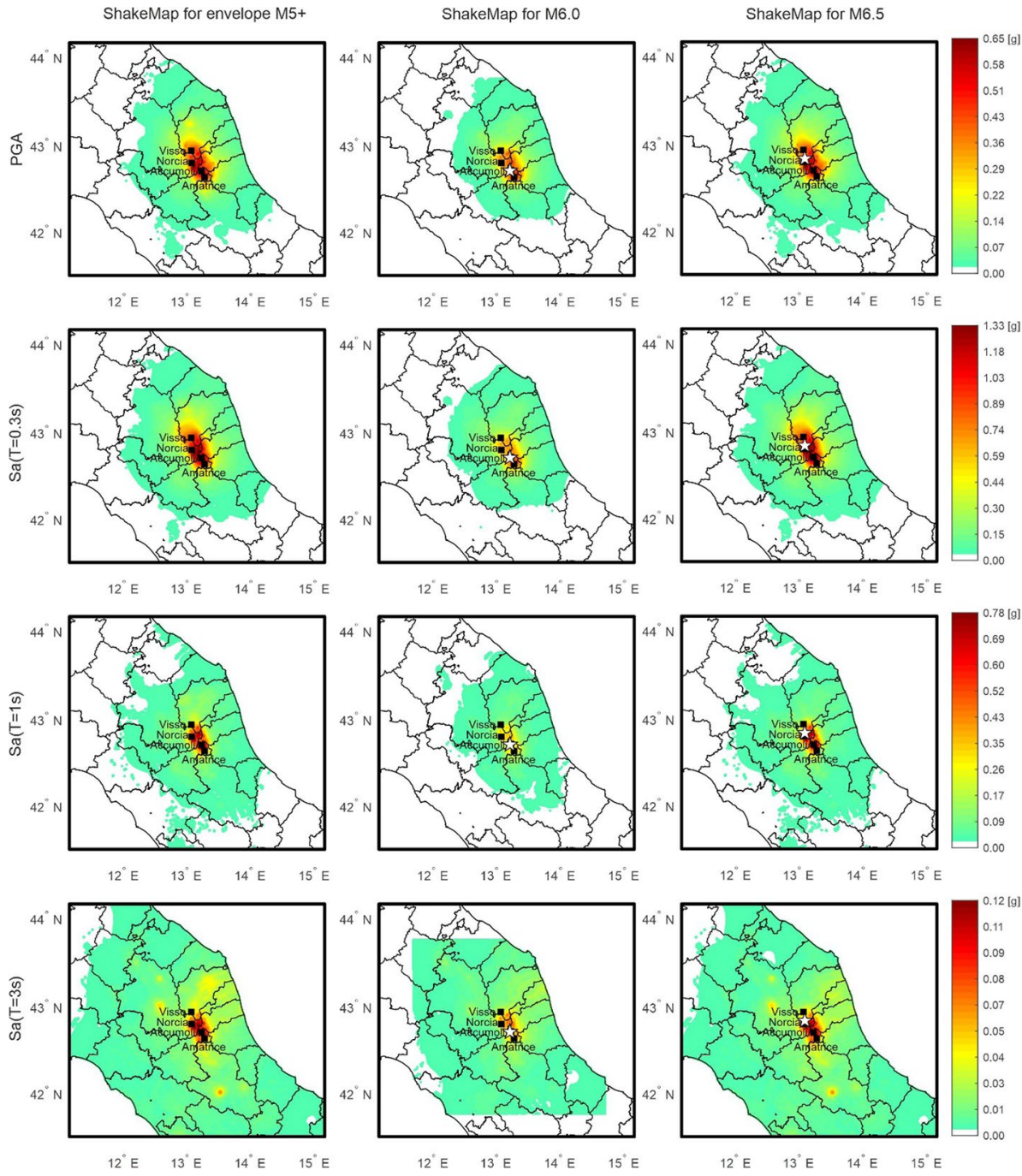

Fig. 4 ShakeMap envelopes of the M5+earthquakes (left), ShakeMap for M6.0 (center) and M6.5 (right) event in terms of PGA, $S a(T=0.3 \mathrm{~s}), S a(T=1 \mathrm{~s})$ and $S a(T=3 \mathrm{~s})$, from top to bottom

in August and October, were exposed to relevant spectral accelerations. Indeed, with reference to the mainshock, a PGA value as high as $0.65 \mathrm{~g}$ is mapped between Norcia and Accumoli, ${ }^{1}$ whereas the largest accelerations in terms of $\operatorname{Sa}(T=0.3 \mathrm{~s})$, equal to $1.33 \mathrm{~g}$, and $S a(T=1 \mathrm{~s})$, that is $0.78 \mathrm{~g}$, are found in the areas surrounding Norcia and between Amatrice and Accumoli, respectively; as pertaining to the longer vibration periods, spectral accelerations are relatively low, being the maximum $S a(T=3 \mathrm{~s})$ value, equal to $0.12 \mathrm{~g}$, close to Norcia.

\footnotetext{
${ }^{1}$ According to Suzuki and Iervolino (2017), the largest PGA of the sequence is equal to $0.87 \mathrm{~g}$ and it was recorded at the Amatrice station during the M6.0 earthquake.
} 
The comparison between the ShakeMap in the leftmost column of the figure and the corresponding for the two main events of the sequence reveals that the pattern of the envelope is quite similar to that pertaining to M6.5. In fact, the ShakeMap for the mainshock provides, among the maps for other events, the largest ground-shaking of the sequence in almost the whole of the investigated region, covering an area ranging between about $50,000 \mathrm{~km}^{2}$ and $60,000 \mathrm{~km}^{2}$, for each spectral ordinate. However, there are also relatively small fractions of the considered region where the largest intensities of the sequence do not coincide with those pertaining to the mainshock. For instance, comparing the envelopes to the ShakeMap specific for M6.0 reveals that, for each spectral ordinate, accelerations estimated for this latter earthquake are the largest among the M5+ events in an area which extends for about $850 \mathrm{~km}^{2}, 450 \mathrm{~km}^{2}, 2700 \mathrm{~km}^{2}$ and $7000 \mathrm{~km}^{2}$ in the case of PGA, $S a(T=0.3 \mathrm{~s}), S a(T=1 \mathrm{~s})$ and $S a(T=3 \mathrm{~s})$, respectively. To give an example, the largest PGA and $S a(T=1 \mathrm{~s}$ ) in the village of Amatrice were due to M6.0 (this will be shown in detail in Sect. 7). Moreover, Fig. 4 allows to identify small areas where, according to ShakeMap estimates, the largest shaking intensities, between August 2016 and January 2017, were caused by the earthquakes of the sequence with magnitude lower than six. It is the case of the yellow shaded areas at the north of Visso in the leftmost panels, where in fact accelerations in terms of PGA, $S a(T=1 \mathrm{~s})$ and $S a(T=3 \mathrm{~s})$ for both the events M6.0 and M6.5 are lower than those provided by the envelopes, which partly motivates the interest in investigating sequence-based ShakeMap rather than those event-specific. Another example in this sense, at least in the considered color scale, is represented by the yellow area at the south of Amatrice for PGA and $S a(T=0.3 \mathrm{~s})$, being it visible in the envelope and not in the M6.0 and M6.5 maps.

Finally, the analysis of the ShakeMap envelopes shows that structures in a significant part of the area struck by 2016-2017 seismic sequence had to withstand severe seismic actions, larger than those enforced by the code for design of new constructions. Although this is everything but surprising, as it is now well known that design actions from probabilistic seismic hazard analysis (PSHA) are expected to be exceeded in the epicentral areas of moderate-to-high magnitude events (e.g., Iervolino 2013; Iervolino et al. 2019b; Cito and Iervolino 2020), it is worthwhile to estimate the extent of the region where such an exceedance has occurred for the individual events and looking at the envelopes, which is the object of the following section.

\section{Exceedance of desing seismic actions}

In this section, the ShakeMap results previously discussed are compared to the seismic actions enforced by the current Italian building code (hereafter NTC18), which provides the spectral pseudo-accelerations (5\% damped) for structural design. In the code, design spectra on rock site conditions are a close approximation of the uniform hazard spectra (extrapolated for spectral ordinates at periods larger than 2.0s) provided by the PSHA study developed for Italy (see Stucchi et al. 2011), the exceedance return period $\left(T_{r}\right)$ of which depends on the performance objective (i.e., the design limit state) considered for the structure.

The maps in Fig. 5 provide, for any site in the considered region, the spectral acceleration from the code spectrum for seismic design of structures, in terms of PGA, $S a(T=0.3 \mathrm{~s}), S a(T=1 \mathrm{~s})$ and $S a(T=3 \mathrm{~s})$, from top to bottom, with exceedance return period equal to 50 (left) and 475 (right) years, corresponding to the damage control and 

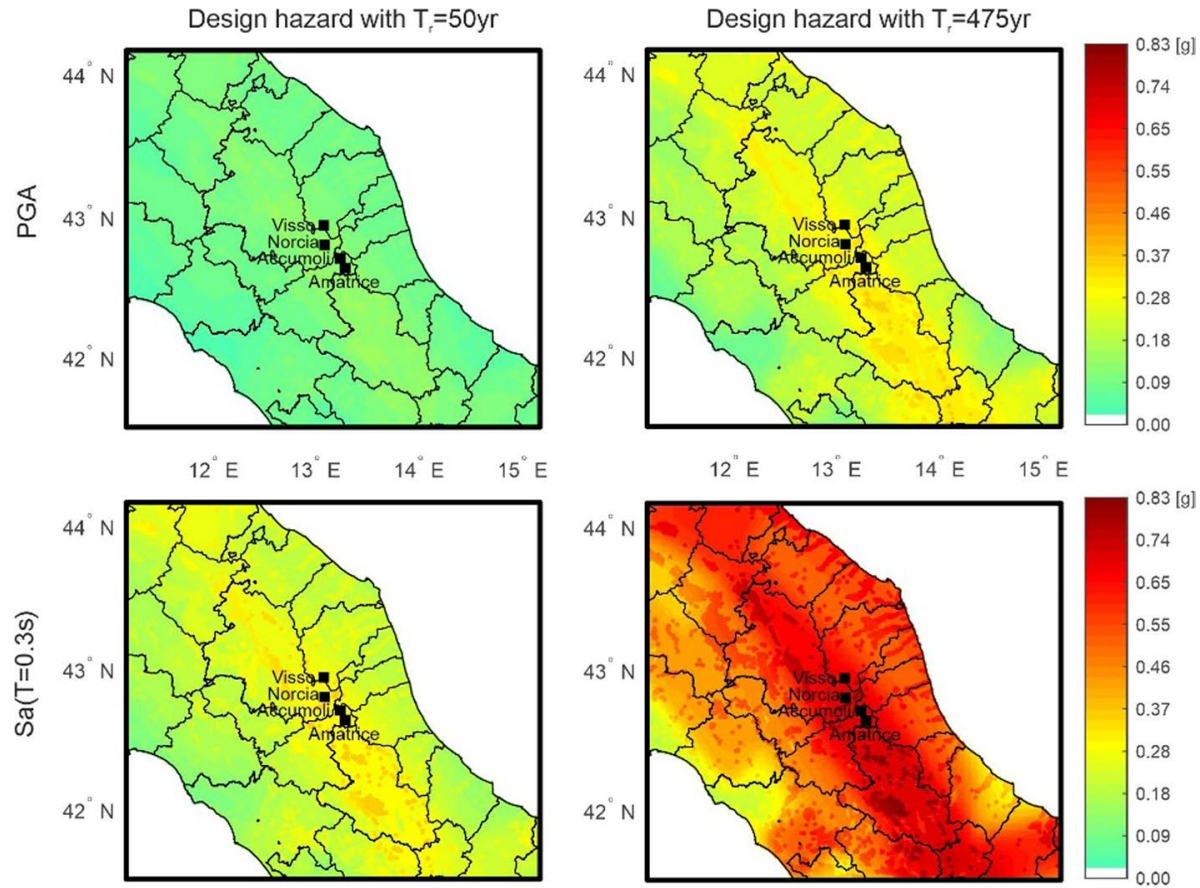

$12^{\circ} \mathrm{E} \quad 13^{\circ} \mathrm{E} \quad 14^{\circ} \mathrm{E} \quad 15^{\circ} \mathrm{E}$
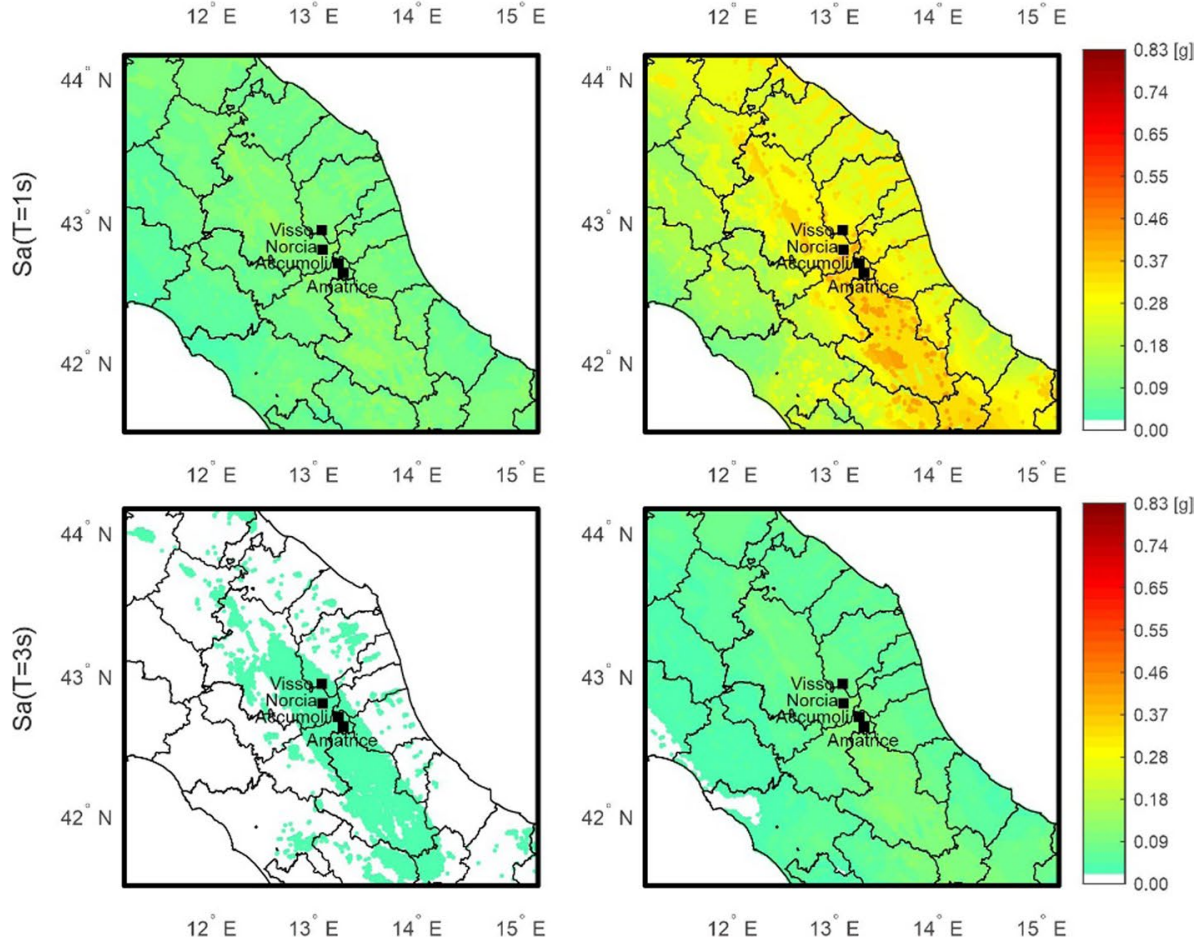

Fig. 5 Design ground motion intensity according to the Italian code in terms of PGA, $S a(T=0.3 \mathrm{~s}), \operatorname{Sa}(T=1 \mathrm{~s})$ and $S a(T=3 \mathrm{~s})$, from top to bottom, with exceedance return period equal to 50 years (left) and 475 years (right). The maps account for soil site conditions according to local geological information used in ShakeMap 
life safety limit state of an ordinary structure according to NTC18, respectively. Spectral accelerations mapped in Fig. 5 account for local soil conditions, via coefficient prescribed by NTC18. Soil conditions attributed to each site are those used by ShakeMap to produce ground motion estimates. ${ }^{2}$

For both return periods, the largest design accelerations are found along the northwestsoutheast direction, that is, along the Apennine mountain chain. In particular, considering $T_{r}=50 \mathrm{yr}$, the largest values are equal to about $0.16 \mathrm{~g}$ in the case of PGA, $0.36 \mathrm{~g}$ for $S a(T=0.3 \mathrm{~s})$ and $0.16 \mathrm{~g}$ for $S a(T=1 \mathrm{~s})$; in the case of $S a(T=3 \mathrm{~s})$, design spectral ordinates are even lower than $0.02 \mathrm{~g}$ in an area covering about $80 \%$ (i.e., the white-colored area) of the investigated region, whereas the largest value is equal to $0.037 \mathrm{~g}$. With reference to $T_{r}=475 \mathrm{yr}$, the PGA, $S a(T=0.3 \mathrm{~s}), S a(T=1 \mathrm{~s})$ and $S a(T=3 \mathrm{~s})$ are as high as $0.36 \mathrm{~g}, 0.83 \mathrm{~g}, 0.44 \mathrm{~g}$ and $0.13 \mathrm{~g}$, respectively.

The comparison between the maps discussed in the previous section and the code-mandated seismic actions for structural design is given in Fig. 6. Each map in the left column allows to identify the sites where the largest estimated acceleration during the sequence exceeds the design actions referring to the two considered return periods. More specifically, sites possibly experiencing exceedance of the spectral ordinate with $T_{r}=50 \mathrm{yr}$ are colored in orange, and those experiencing also the exceedance of intensity measure with $T_{r}=475 \mathrm{yr}$ are depicted in red. The maps in the central and right column identify those sites in which the exceedance should have occurred due to the M6.0 and M6.5 earthquakes, respectively. Maps referring to the envelope factually identify sites that might have experienced at least one exceedance of the design spectral ordinate between August 24th 2016 and January 18th 2017 due to the M5+ events of the sequence.

Looking at the figure vertically, it appears that, considering the mainshock and - therefore - the envelope, the patterns of the maps for PGA and $S a(T=0.3 \mathrm{~s})$ are quite similar, coherently with the ShakeMap discussed in the previous section, whereas both the orange and red colored areas reduce from PGA to $\operatorname{Sa}(T=0.3 \mathrm{~s})$ in the case of M6.0. Considering $S a(T=1 \mathrm{~s})$, it appears that the exceedance areas due to the mainshock and those from the envelope are smaller than those in the maps above. For example, the red colored area in the leftmost map does not include the sites of Amatrice and Visso, meaning that it is expected that they did not experience any exceedance of the high vibration period spectral ordinates from the code spectrum with $T_{r}=475 \mathrm{yr}$, differently from what happened at the high frequencies (this will be further discussed in Sect. 7). This is even more evident for $S a(T=3 \mathrm{~s})$, as the red colored area is further reduced with respect to $S a(T=1 \mathrm{~s})$ and does not include any of the four sites represented in the maps. Also, as it pertains to M6.0, exceedance of the design $S a(T=1 \mathrm{~s})$ and $S a(T=3 \mathrm{~s})$ values is only found in the case of $T_{r}=50 \mathrm{yr}$.

More interestingly, considering the same intensity measure, it is found that both orange and red areas in the left panel are quite similar to those in the rightmost map, which refers to the largest magnitude earthquake of the sequence, and this is a consequence of what discussed in the previous section. More specifically, considering the whole sequence, the areas possibly experiencing at least one exceedance between August 2016 and January 2017 are clearly larger than those found for the M6.5 earthquake, yet slightly, for almost all the spectral ordinates and exceedance return periods herein considered. In fact, most of the

\footnotetext{
2 This is for consistency of comparison between ShakeMap and design actions; however, it was verified that also using a recent soil classification for Italy, which can be found in Forte et al. (2019), leads to analogous results.
} 
Exc. area for envelope M5+
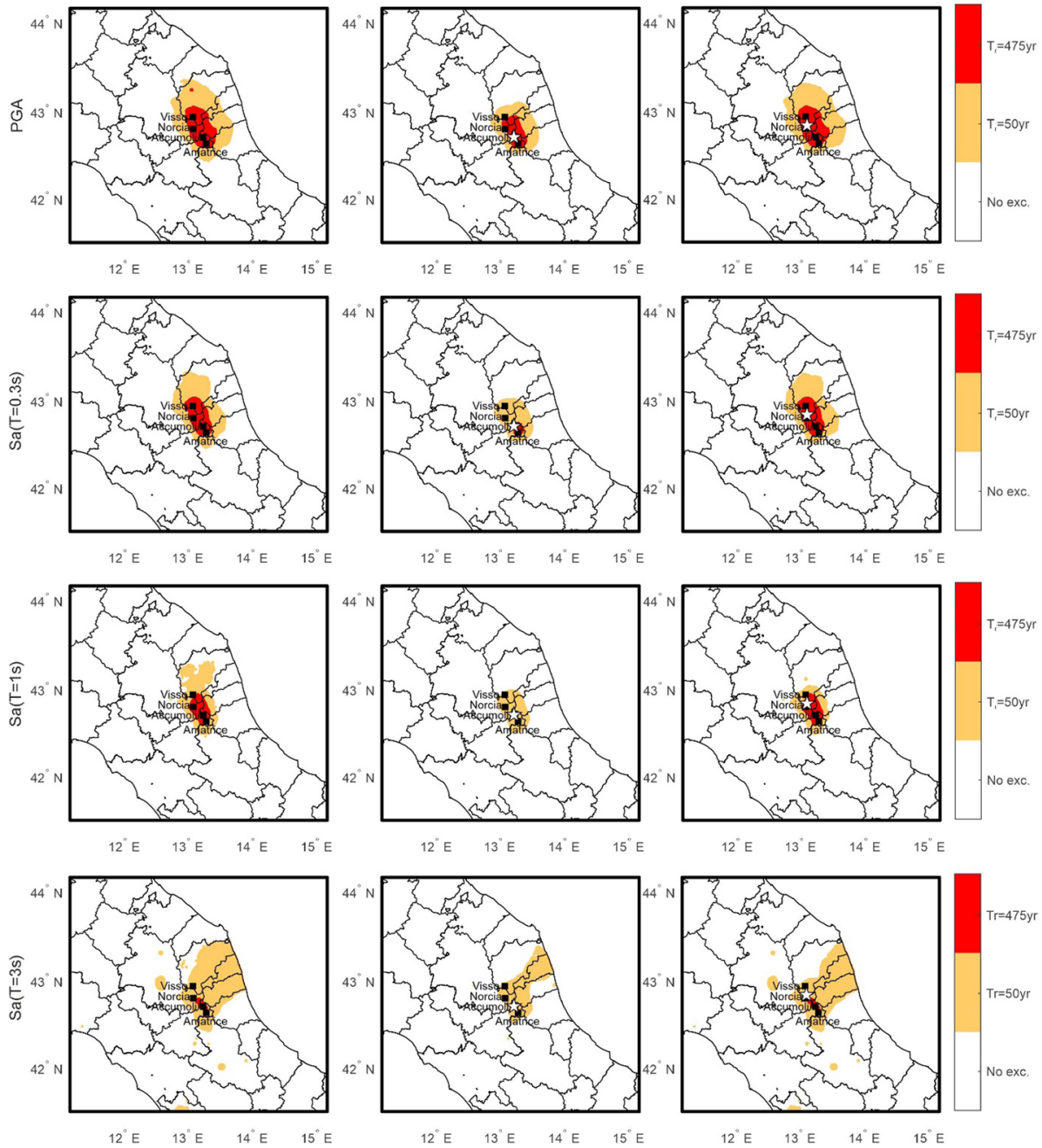

Fig. 6 Estimated exceedance of the spectral ordinate of the design spectra with $T_{r}=50 \mathrm{yr}$ and $T_{r}=475 \mathrm{yr}$ considering the ShakeMap envelopes of the M5+ earthquakes (left), ShakeMap for M6.0 (center) and M6.5 (right) event in terms of PGA, $S a(T=0.3 \mathrm{~s}), S a(T=1 \mathrm{~s})$, and $S a(T=3 \mathrm{~s})$, from top to bottom

M5+earthquakes caused exceedances in an area, around their epicenter, which is generally enclosed in that of the mainshock. This is further quantified in the next section.

To close this section, the effect of the uncertainty provided by ShakeMap on the exceedance areas from the envelopes is explored. To this aim, for each of the four intensity measures, two envelopes are obtained: the first one is obtained enveloping the ShakeMap for the M5+ events where, to each grid point, the value representing the uncertainty on the ground motion estimate is subtracted while to obtain the second envelope, it is added to the (logarithm) of the ground motion estimate of each event (values are provided along with ShakeMap data; see Data availability). These two envelopes are considered as lower and 
Exc. area for envelope M5+ plus one std. error

Exc. area for envelope M5+ minus one std. error
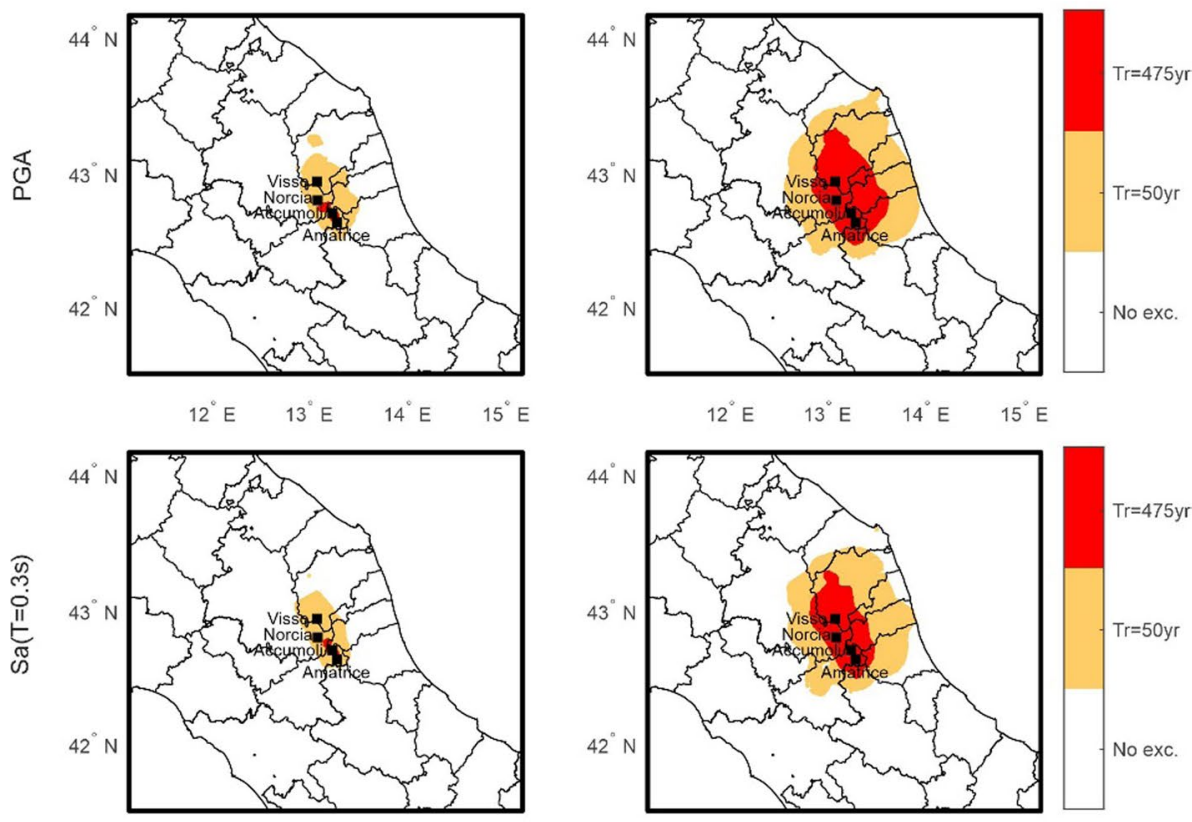

$12^{\circ} \mathrm{E} \quad 13^{\circ} \mathrm{E} \quad 14^{\circ} \mathrm{E} \quad 15^{\circ} \mathrm{E}$

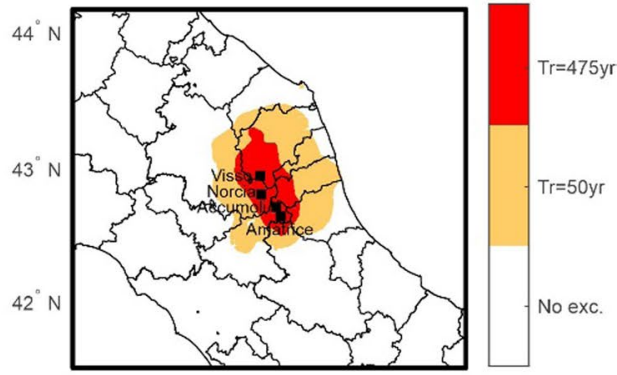

$12^{\circ} \mathrm{E} \quad 13^{\circ} \mathrm{E} \quad 14^{\circ} \mathrm{E} \quad 15^{\circ} \mathrm{E}$
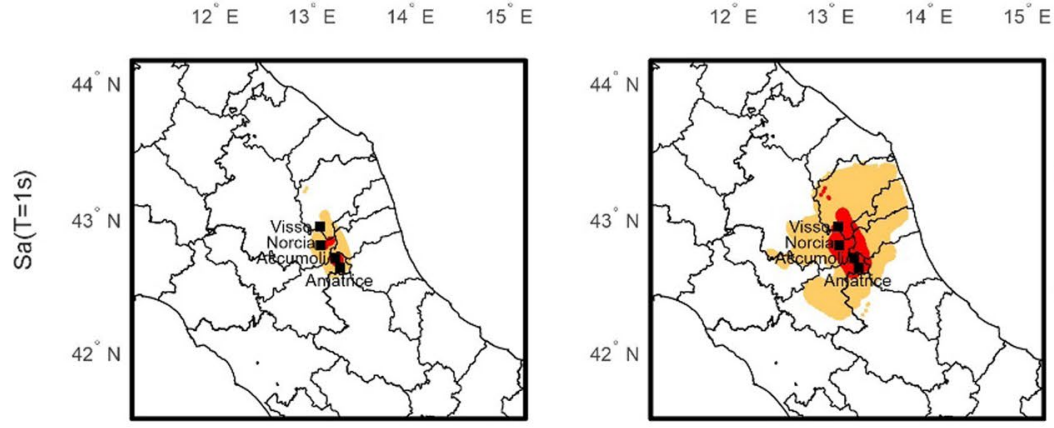

$12^{\circ} \mathrm{E} \quad 13^{\circ} \mathrm{E} \quad 14^{\circ} \mathrm{E} \quad 15^{\circ} \mathrm{E}$

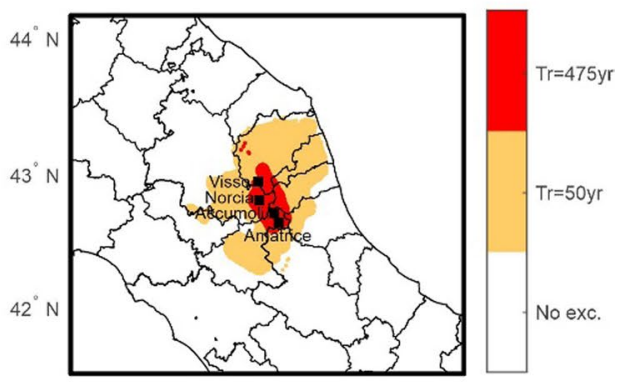

$12^{\circ} \mathrm{E} \quad 13^{\circ} \mathrm{E} \quad 14^{\circ} \mathrm{E} \quad 15^{\circ} \mathrm{E}$

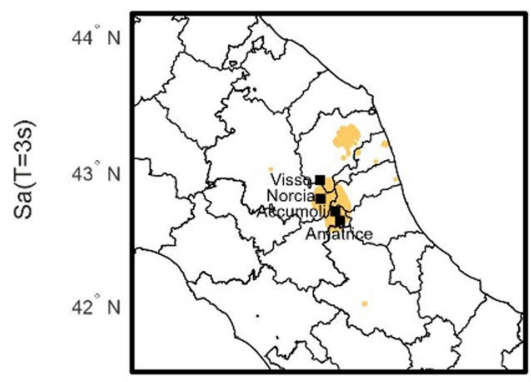

$12^{\circ} \mathrm{E} \quad 13^{\circ} \mathrm{E} \quad 14^{\circ} \mathrm{E} \quad 15^{\circ} \mathrm{E}$

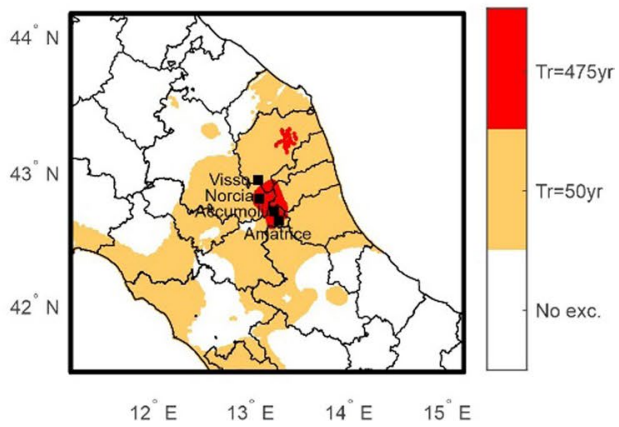

Fig. 7 Exceedance of the spectral ordinate of the design spectra with $T_{r}=50 \mathrm{yr}$ and $T_{r}=475 \mathrm{yr}$ considering the ShakeMap envelopes of the M5+earthquakes plus (left) and minus (right) one standard error, in terms of PGA, $S a(T=0.3 \mathrm{~s}), S a(T=1 \mathrm{~s})$, and $S a(T=3 \mathrm{~s})$, from top to bottom 

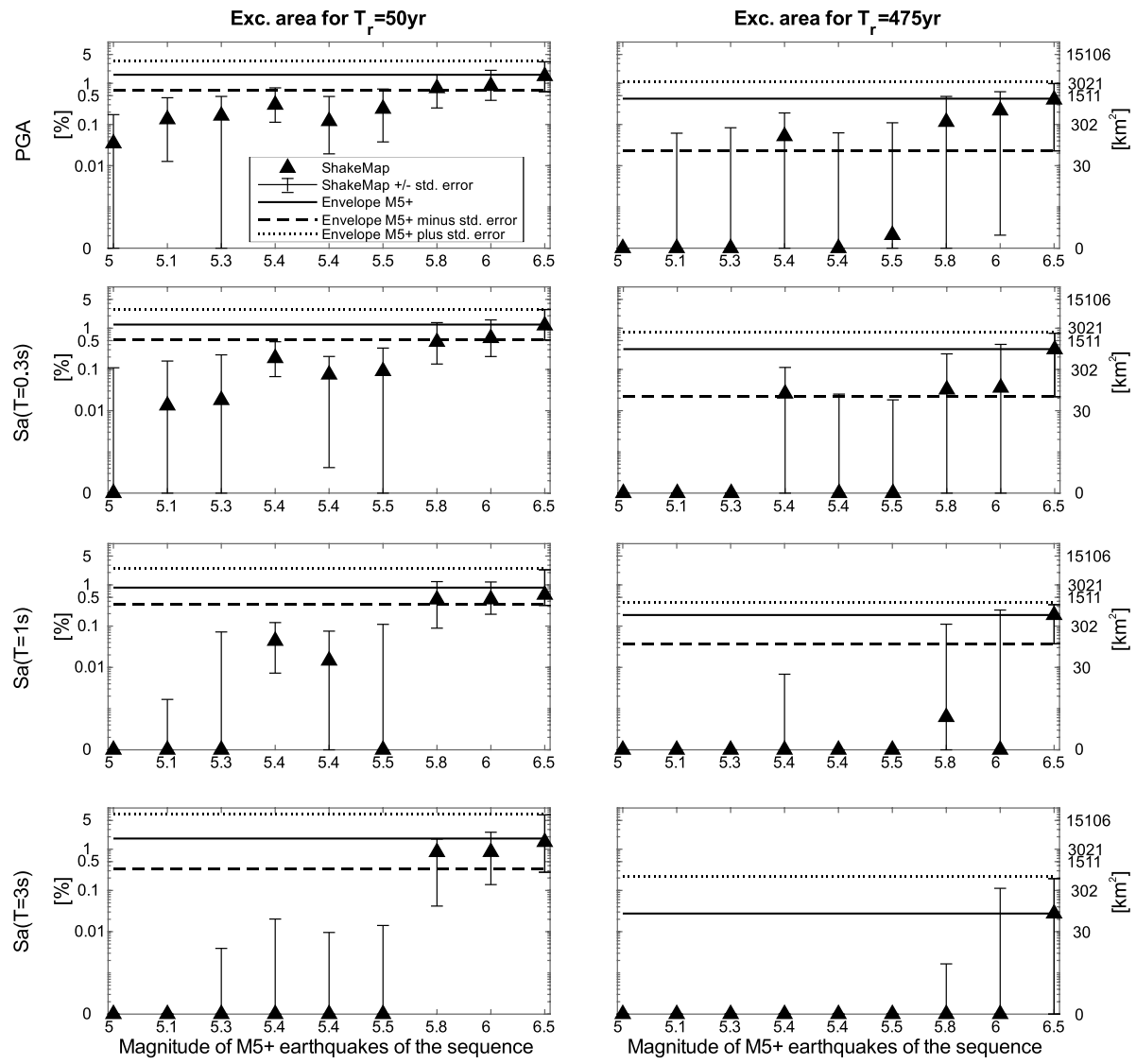

Fig. 8 Estimated size of the area experiencing exceedance of the code spectra with $T_{r}=50 \mathrm{yr}$ (left) and $T_{r}=475 \mathrm{yr}$ (right), in term of PGA, $S a(T=0.3 \mathrm{~s}), S a(T=1 \mathrm{~s})$ and $S a(T=3 \mathrm{~s})$, from top to bottom, due to the M5+ events of the sequence, as a function of the increasing magnitude. Horizontal lines refer to the exceedance areas from the envelopes

upper bounds to the ShakeMap envelopes, and Fig. 7 shows, for each intensity measure, the design actions (i.e., those from Fig. 5) exceedance areas for the lower bound (left) and upper bound (right), in the very same way as in Fig. 6. The figure reveals that the uncertainty in the ShakeMap estimates has a not negligible effect in assessing the area experiencing at least one exceedance between August 2016 and January 2017. In fact, for each return period and spectral ordinate, the ShakeMap uncertainties imply that the exceedance area can be more than twice the counterpart in the leftmost panel of Fig. 6; at the same time, accounting for the uncertainty reveals that the exceedance area from Fig. 6 can be reduced by half at least. This is explored in more detail in the next section. 


\section{Quantifying exceedace areas}

In Fig. 8 the estimated exceedance areas are quantified for each of the M5+ events and for the envelopes, based on the results discussed in the previous section. The panels in the figure provide on the right vertical axis a quantification of the areas exposed to exceedance of design seismic actions with $T_{r}=50 \mathrm{yr}$ (left panels) and $T_{r}=475 \mathrm{yr}$ (right panels) in term of PGA, $S a(T=0.3 \mathrm{~s}), S a(T=1 \mathrm{~s})$ and $S a(T=3 \mathrm{~s})$, due to each of the nine M5+ earthquakes of the sequence, as a function of the increasing event magnitude; the left vertical axis shows the exceedance areas in terms of percentage of the Italian territory. Moreover, the exceedance areas from the envelopes are represented by the horizontal continuous lines. Finally, the bars and the horizontal dotted lines in each panel quantify the effect of the ShakeMap uncertainty on the exceedance area found for each of the M5+ events and the envelopes, respectively.

Looking at the figure, it can be preliminarily observed that, on average over the nine M5+ events, exceedance areas for the low vibration periods tend to be larger than the counterparts for $S a(T=1 \mathrm{~s})$ and $S a(T=3 \mathrm{~s})$. If the design intensity is not put into question, this may also be related to the relationship between the frequency content and attenuation features of ground motion and the event magnitude (e.g., Iervolino et al. 2011). Moreover, for any exceedance return period and spectral ordinate, the exceedance area for M6.5 is only slightly smaller than the area experiencing at least one exceedance due to the nine M5+events of the sequence; i.e., that from the envelope. More specifically, looking at $T_{r}=50 \mathrm{yr}$, it can be seen that the exceedance area for the envelope is equal to about 4800 $\mathrm{km}^{2}, 3700 \mathrm{~km}^{2}, 2600 \mathrm{~km}^{2}$ and $5500 \mathrm{~km}^{2}$, in the case of PGA, $S a(T=0.3 \mathrm{~s}), S a(T=1 \mathrm{~s})$ and $S a(T=3 \mathrm{~s})$, respectively. For the mainshock, these areas slightly reduce, being equal to about $4500 \mathrm{~km}^{2}$ for PGA, $3500 \mathrm{~km}^{2}$ for $S a(T=0.3 \mathrm{~s}), 1700 \mathrm{~km}^{2}$ for $S a(T=1 \mathrm{~s})$ and 4500 $\mathrm{km}^{2}$ for $S a(T=3 \mathrm{~s})$. Looking at $T_{r}=475 \mathrm{yr}$, and considering the envelope, the exceedance area is reduced by a factor of about four in the case of PGA, $S a(T=0.3 \mathrm{~s})$ and $S a(T=1 \mathrm{~s})$, being equal to about $1300 \mathrm{~km}^{2}, 900 \mathrm{~km}^{2}$ and $600 \mathrm{~km}^{2}$. These areas are almost coincident to those found for the mainshock. In the case of $S a(T=3 \mathrm{~s})$, the area exposed to at least one exceedance of the ordinate of code spectrum with $T_{r}=475 \mathrm{yr}$ is equal to the exceedance area for M6.5, being both about $80 \mathrm{~km}^{2}$ wide.

When passing from M6.5 to M6.0, the estimated exceedance area reduces by a factor of about two in the case of PGA for both return periods; the same was also found in the case of $S a(T=0.3 \mathrm{~s})$ for $T_{r}=50 \mathrm{yr}$, whereas the size reduces by almost an order of magnitude for $T_{r}=475 \mathrm{yr}$. As it pertains to $S a(T=1 \mathrm{~s})$, M6.0 and M6.5 caused an (almost) equal exceedance area in the case of $T_{r}=50 \mathrm{yr}$, while exceedance of the design action with $T_{r}=475 \mathrm{yr}$ is null for M6.0. With reference to $S a(T=3 \mathrm{~s})$, exceedance area due to M6.0 is half that for the mainshock in the case of $T_{r}=50 \mathrm{yr}$, whereas it is estimated no exceedance for $T_{r}=475 \mathrm{yr}$.

When looking at the events with magnitude lower than 6.0, the exceedance areas tend to very rapidly reduce in size, especially for the longer period spectral ordinates; in fact, no exceedance of design actions corresponding to $T_{r}=475 \mathrm{yr}$ is found for $S a(T=1 \mathrm{~s})$ in the case of the earthquakes with magnitude between 5.0 and 5.5. Even more evident, the $S a(T=3 \mathrm{~s})$ of the code spectrum with $T_{r}=475 \mathrm{yr}$ is exceeded only because of the mainshock while, considering $T_{r}=50 \mathrm{yr}$, only three exceedances are estimated during the sequence, that is, due to three largest magnitude events. In the case of PGA, the M5.4 event occurred on October 26th caused a $150 \mathrm{~km}^{2}$ wide exceedance area of the design action with $T_{r}=475 \mathrm{yr}$, despite the relatively low magnitude, while it is negligible (i.e., about 
one square kilometer) in the case of M5.5. $S a(T=0.3 \mathrm{~s})$ is in an intermediate situation, as expected. Finally, the exceedance area due to the mainshock is very close in size with respect to that of the envelope for all spectral accelerations and return periods herein considered.

Considering the effect of the ShakeMap uncertainty, it appears that the exceedance area of the design action with $T_{r}=475 \mathrm{yr}$ from the envelope is in the $70-3320 \mathrm{~km}^{2}$ range in the case of PGA, 70-2400 $\mathrm{km}^{2}$ in the case of $S a\left(T=0.3 \mathrm{~s}\right.$ ), and $110-1120 \mathrm{~km}^{2}$ in the case of $S a(T=1 \mathrm{~s})$; as pertaining to $S a(T=3 \mathrm{~s})$, exceedance area can even be null (this motivates the absence of the dotted line below the continuous one in the bottom-right panel of Fig. 8) or as high as $660 \mathrm{~km}^{2}$. With reference to $T_{r}=50 \mathrm{yr}$, the intervals of the exceedance area are $2050-10,260 \mathrm{~km}^{2}$ for PGA, $1600-8700 \mathrm{~km}^{2}$ for $S a(T=0.3 \mathrm{~s}), 1000-7800 \mathrm{~km}^{2}$ for $S a(T=1 \mathrm{~s})$ and $990-21,800 \mathrm{~km}^{2}$ for $S a(T=3 \mathrm{~s})$.

\subsection{Exceedance fraction of the Italian territory}

It is easy to show that, in fifty years, it is expected that ten percent of the sites experiences exceedance of the ground-shaking intensity values from a seismic hazard map referring to $T_{r}=475 \mathrm{yr}$. This is because, in the hypotheses of PSHA, $T_{r}=475 \mathrm{yr}$ corresponds to $10 \%$ exceedance probability in fifty years at the site of interest. Therefore, exceedance in fifty years, at each site, is a Bernoulli random variable with mean equal to 0.1. Considering the bulk of sites the map refers to, the expected value of the number of sites experiencing exceedance in that time-frame is just the sum of the expected values of the Bernoulli random variables at all the sites (recall that the mean of any sum of random variables is not affected by the possible stochastic dependency among them). Therefore, the expected number of sites experiencing exceedance is ten percent of the total number of sites. For the same reasoning, it is expected that, in fifty years, sixty-three percent of the sites experience exceedance of the shaking values from the map referring to $T_{r}=50 \mathrm{yr}$. (Note, however, that these fractions refer to exceedances caused by mainshocks, as classical PSHA is based on declustered seismic catalogs, where aftershocks and foreshocks are removed.)

That said, Fig. 8 shows that the portion of the national territory that it is estimated has experienced at least one exceedance of the spectral ordinate (i.e., that from ShakeMap envelopes) on the left vertical axis. For $T_{r}=50 \mathrm{yr}$ such an area is equal to about $1.60 \%$ for PGA, $1.22 \%$ for $S a(T=0.3 \mathrm{~s}), 0.86 \%$ for $S a(T=1 \mathrm{~s})$ and $1.82 \%$ for $S a(T=3 \mathrm{~s})$. With respect to $T_{r}=475 \mathrm{yr}$, it reduces to $0.42 \%, 0.31 \%, 0.19 \%$ and $0.03 \%$ in the case of PGA, $S a(T=0.3 \mathrm{~s}), S a(T=1 \mathrm{~s})$ and $S a(T=3 \mathrm{~s})$, respectively. These percentages, together with those pertaining to the nine M5+ events of the sequence, are summarized in Table 1, which also shows the exceedance areas in absolute terms discussed in the previous section.

Percentages from the envelopes are just slightly larger than (or equal to) those found for M6.5. In fact, due to the largest event of the sequence, exceedance of the PGA, $S a(T=0.3 \mathrm{~s}), S a(T=1 \mathrm{~s})$ and $S a(T=3 \mathrm{~s})$ of the code spectrum with $T_{r}=50 \mathrm{yr}$ was found in the $1.49 \%, 1.16 \%, 0.57 \%$, and $1.49 \%$ of the Italian territory, respectively. Considering $T_{r}=475 \mathrm{yr}$, these percentages reduce to $0.40 \%$ for PGA, $0.31 \%$ for $S a(T=0.3 \mathrm{~s}), 0.19 \%$ for $S a(T=1 \mathrm{~s})$ and $0.03 \%$ for $S a(T=3 \mathrm{~s})$. With reference to almost all spectral ordinates and return periods, the M5.8 and M6.0 earthquakes caused exceedance in areas of the same order of magnitude. The only exception in this sense is found looking at the $\operatorname{Sa}(T=1 \mathrm{~s})$ of the code spectrum with $T_{r}=475 \mathrm{yr}$, being null the estimated exceedance area due to M6.0 and larger than zero in the case of M5.8 (even if the latter actually approaches zero). 
Table 1 Fraction of the Italian territory exposed to exceedance according to ShakeMap estimates, in percentage terms and size of the areas in term of square kilometers for the M5+events of the sequence and the envelopes

\begin{tabular}{|c|c|c|c|c|c|c|c|c|c|c|c|}
\hline & & M5.0 & M5.1 & M5.3 & M5.4 & M5.4 & M5.5 & M5.8 & M6.0 & M6.5 & Envelope \\
\hline \multirow[t]{6}{*}{ PGA } & $T_{r}[\mathrm{yr}]$ & \multicolumn{10}{|c|}{ Exceedance area $[\%]$} \\
\hline & 50 & 0.03 & 0.13 & 0.16 & 0.30 & 0.12 & 0.24 & 0.76 & 0.86 & 1.49 & 1.60 \\
\hline & 475 & 0 & 0 & 0 & 0.05 & 0 & $2.08 \mathrm{E}-04$ & 0.12 & 0.22 & 0.40 & 0.42 \\
\hline & $T_{r}[\mathrm{yr}]$ & \multicolumn{10}{|c|}{ Exceedance area $\left[\mathrm{km}^{2}\right]$} \\
\hline & 50 & 105 & 402 & 493 & 909 & 364 & 724 & 2286 & 2605 & 4494 & 4846 \\
\hline & 475 & 0 & 0 & 0 & 157 & 0 & 1 & 348 & 658 & 1211 & 1276 \\
\hline \multirow[t]{6}{*}{$\operatorname{Sa}(T=0.3 \mathrm{~s})$} & $T_{r}[\mathrm{yr}]$ & \multicolumn{10}{|c|}{ Exceedance area $[\%]$} \\
\hline & 50 & 0 & 0.01 & 0.02 & 0.19 & 0.07 & 0.09 & 0.46 & 0.58 & 1.16 & 1.22 \\
\hline & 475 & 0 & 0 & 0 & 0.03 & 0 & 0 & 0.03 & 0.04 & 0.31 & 0.31 \\
\hline & $T_{r}[\mathrm{yr}]$ & \multicolumn{10}{|c|}{ Exceedance area $\left[\mathrm{km}^{2}\right]$} \\
\hline & 50 & 0 & 40 & 54 & 568 & 226 & 274 & 1405 & 1737 & 3514 & 3694 \\
\hline & 475 & 0 & 0 & 0 & 78 & 0 & 0 & 98 & 109 & 925 & 940 \\
\hline \multirow[t]{6}{*}{$S a(T=1 \mathrm{~s})$} & $T_{r}[\mathrm{yr}]$ & \multicolumn{10}{|c|}{ Exceedance area $[\%]$} \\
\hline & 50 & 0 & 0 & 0 & 0.04 & 0.01 & 0 & 0.44 & 0.45 & 0.57 & 0.86 \\
\hline & 475 & 0 & 0 & 0 & 0 & 0 & 0 & $6.20 \mathrm{E}-04$ & 0 & 0.19 & 0.19 \\
\hline & $T_{r}[\mathrm{yr}]$ & \multicolumn{10}{|c|}{ Exceedance area $\left[\mathrm{km}^{2}\right]$} \\
\hline & 50 & 0 & 0 & 0 & 132 & 44 & 0 & 1332 & 1344 & 1737 & 2590 \\
\hline & 475 & 0 & 0 & 0 & 0 & 0 & 0 & 2 & 0 & 561 & 561 \\
\hline \multirow[t]{6}{*}{$\operatorname{Sa}(T=3 \mathrm{~s})$} & $T_{r}[\mathrm{yr}]$ & \multicolumn{10}{|c|}{ Exceedance area $[\%]$} \\
\hline & 50 & 0 & 0 & 0 & 0 & 0 & 0 & 0.85 & 0.85 & 1.49 & 1.82 \\
\hline & 475 & 0 & 0 & 0 & 0 & 0 & 0 & 0 & 0 & 0.03 & 0.03 \\
\hline & $T_{r}[\mathrm{yr}]$ & \multicolumn{10}{|c|}{ Exceedance area $\left[\mathrm{km}^{2}\right]$} \\
\hline & 50 & 0 & 0 & 0 & 0 & 0 & 0 & 2568 & 2578 & 4514 & 5495 \\
\hline & 475 & 0 & 0 & 0 & 0 & 0 & 0 & 0 & 0 & 83 & 83 \\
\hline
\end{tabular}

For the events in the range between M5.0 and M5.5, the largest number of sites exposed to exceedance is found for the M5.4 event occurred in proximity of Visso on October 26th. According to ShakeMap estimates, ground motion intensity is larger than the spectral ordinate of the code spectrum with $T_{r}=50 \mathrm{yr}$ for the $0.30 \%, 0.19 \%$ and $0.04 \%$ of the national territory for PGA, $S a(T=0.3 \mathrm{~s})$ and $S a(T=1 \mathrm{~s})$, respectively. In the case of $T_{r}=475 \mathrm{yr}$, these percentages are lower than $0.10 \%$ for PGA and $S a(T=0.3 \mathrm{~s})$, whereas no exceedance is found for $\operatorname{Sa}(T=1 \mathrm{~s})$. As pertaining to $\operatorname{Sa}(T=3 \mathrm{~s})$, although thresholds from the code spectra with $T_{r}=50 \mathrm{yr}$ and $T_{r}=475 \mathrm{yr}$ are relatively low, no exceedance is estimated for earthquakes with magnitude equal to or less than 5.5.

When including ShakeMap uncertainty, the fraction of Italy experiencing at least one exceedance of the design seismic actions with $T_{r}=475 \mathrm{yr}$ is in the range $0.02-1.10 \%$ in the case of PGA, $0.02-0.80 \%$ in the case of $S a(T=0.3 \mathrm{~s}), 0.04-0.37 \%$ in the case of $S a(T=1 \mathrm{~s})$, and $0-0.22 \%$ for $S a(T=3 \mathrm{~s})$. When considering $T_{r}=50 \mathrm{yr}$, these intervals are comparatively larger, being $0.68-3.39 \%$ for PGA, $0.53-2.87 \% S a(T=0.3 \mathrm{~s}), 0.34-2.58 \%$ for $S a(T=1 \mathrm{~s})$, and $0.33-7.21 \%$ for $S a(T=3 \mathrm{~s})$. 


\subsection{Insights on October 26th M5.4}

It has been shown that the exceedance area tends to increase with magnitude. However, this is a general trend, and some exceptions may be found. An evident example in this sense is the M5.4 event occurred near Visso on October 26th. For each return period and spectral ordinate, the estimated exceedance area due to this earthquake is larger than that found for M5.5. Moreover, M5.4 caused exceedance of code-mandated seismic actions in an area which is not significatively lower than M5.8, especially at the low vibration periods (see also Table 1). Some insights on these issues are given in the following.

First, it has to be mentioned that magnitude is not fully exhaustive in describing earthquake effects in its epicentral area; for instance, the two M5.4 events of the sequence caused different exceedance areas. This issue may be significant, and this is why ground motion prediction equations include an inter-event residual term, which explains systematic differences in ground motion amplitudes in earthquakes of the same magnitude. Second, still with reference to the same spectral ordinate, the comparison of the exceedance areas due to different events cannot dismiss the fact that design thresholds (for the same return period) can be different in the areas around the earthquake epicenters; e.g., because of the site conditions. For example, hazard maps in Fig. 5 show that the thresholds in the epicentral area of M5.4 in proximity of Visso are slightly lower than those in proximity of the epicenter of M5.5 at the south of Amatrice. Finally, when comparing the exceedance areas for the different spectral ordinates, one should consider that, if the design intensity threshold is not put into question, the spectral content and consequently attenuation features with distance, tend to systematically vary with magnitude, as mentioned. The consequence is that the difference between exceedance areas estimated for the low magnitude events and those for M5.5+ is more remarkable in the case of $\operatorname{Sa}(T=1 \mathrm{~s})$ and $\operatorname{Sa}(T=3 \mathrm{~s})$, as shown in Fig. 8.

\section{Shock history}

It has been discussed that nine earthquakes with magnitude equal to or larger than five hit central Italy in the time period spanning from August 2016 to January 2017. Among these, three events with magnitude between 5.8 and 6.5 occurred near the villages of Accumoli, Amatrice, Norcia and Visso (see Sect. 4), where the most relevant effects of the seismic sequence were found according to the ShakeMap envelopes, in fact (see Fig. 4). Thus, it may be worthwhile to explore the number of exceedances of the design seismic actions at each site due to the nine M5+events, which cannot be inferred from the envelopes, while it may be relevant from the structural engineering perspective. In fact, this points at the relevance of seismic damage accumulation in short-term, when structural repair is unfeasible, an issue that is not yet accounted for explicitly by building codes. To this aim, the groundshaking at the four sites due to the M5+earthquakes are presented in Figs. 9, 10, 11 and 12, referring to Accumoli, Amatrice, Norcia and Visso, respectively. Each figure considers the shock history for each of the intensity measures considered in the previous sections. The round markers show the shock intensity, following the temporal order of earthquakes occurrence, as provided by the event-specific ShakeMap for the point which is the closest to the site declared in the figure; this is considered meaningful being ShakeMap grids dense. The magnitude of each event is also recalled and the horizontal black lines denote the design seismic actions, with $T_{r}=50 \mathrm{yr}$ and $T_{r}=475 \mathrm{yr}$, at the considered location. 


\section{Accumoli}
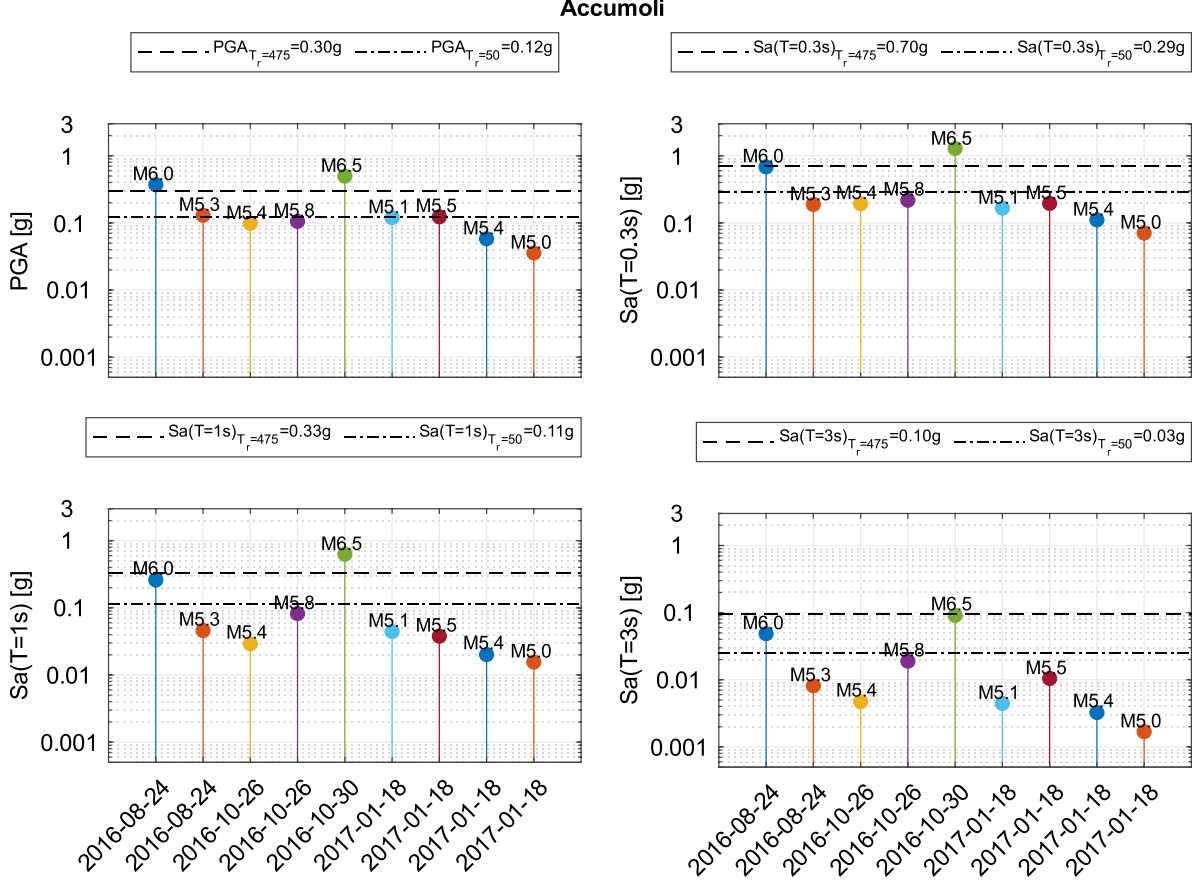

Fig. 9 Ground motion intensity, in terms of PGA, $S a(T=0.3 \mathrm{~s}), S a(T=1 \mathrm{~s})$ and $S a(T=3 \mathrm{~s})$, for Accumoli according to ShakeMap for each of the M5+ earthquakes of the sequence

Looking at the figures, it can be first observed that, during the sequence, the four sites might have experienced at least one exceedance of the design seismic actions repeatedly for the low vibration periods. In fact, even considering $T_{r}=475 \mathrm{yr}$, the PGA of the code spectrum was possibly exceeded more than once at three out of four sites. The number of exceedances reduces at the longer vibration periods. Still with reference to $T_{r}=475 \mathrm{yr}$ ,the design $\operatorname{Sa}(T=1 \mathrm{~s})$ was exceeded once at two out of four sites, and no exceedance can be found at the others. In the case of $\operatorname{Sa}(T=3 \mathrm{~s})$, none of the sites experienced exceedance of the threshold from the code spectrum with $T_{r}=475 \mathrm{yr}$.

Looking at Fig. 9, one can observe that, according to ShakeMap, the PGA from the code spectrum with $T_{r}=475 \mathrm{yr}$ was exceeded twice at Accumoli, that is, on August 24th and October 30th, while design $S a(T=0.3 \mathrm{~s})$ and $S a(T=1 \mathrm{~s})$ are smaller than those given by ShakeMap only in the case of the mainshock. In fact, apart from the magnitude of both the events, the distance of the site from the epicenters (i.e., the epicentral distance) is smaller than $2 \mathrm{~km}$ and $20 \mathrm{~km}$ for the M6.0 and M6.5 events, respectively (see Fig. 13). According to Fig. 10, the latter events are also the only of the sequence that have caused exceedance of the code-mandated PGA and $S a(T=0.3 \mathrm{~s})$ at Amatrice, even if epicentral distances are larger than those for Accumoli (i.e., $10 \mathrm{~km}$ and about $30 \mathrm{~km}$ for M6.0 and M6.5, respectively). As it pertains to $S a(T=1 \mathrm{~s})$, no exceedance was found during the whole sequence. Looking at Norcia, whose shock history is shown in Fig. 11, design spectral ordinates in terms of PGA, $S a(T=0.3 \mathrm{~s})$ and $S a(T=1 \mathrm{~s})$ were only exceeded due to the closest among the nine M5+events, that is, the mainshock. 


\section{Amatrice}

$-\ldots-. P \mathrm{PA}_{\mathrm{T}_{\mathrm{r}}=475}=0.30 \mathrm{~g} \ldots \ldots \mathrm{PGA}_{\mathrm{T}_{\mathrm{r}}=50}=0.12 \mathrm{~g}$

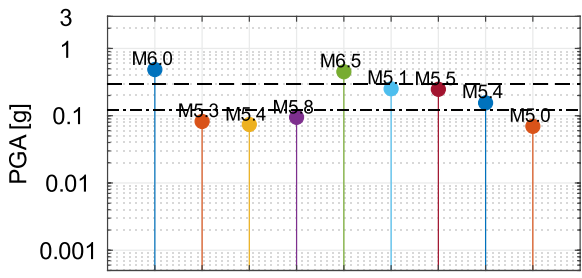

$-\ldots . . \mathrm{Sa}(\mathrm{T}=1 \mathrm{~s})_{\mathrm{T}_{\mathrm{r}}=475}=0.33 \mathrm{~g} \ldots \ldots \mathrm{Sa}(\mathrm{T}=1 \mathrm{~s})_{\mathrm{T}_{\mathrm{r}}=50}=0.11 \mathrm{~g}$

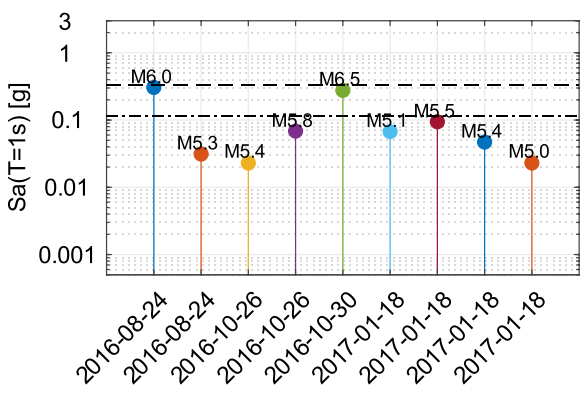

$-\ldots-. \mathrm{Sa}(\mathrm{T}=0.3 \mathrm{~s})_{T_{\mathrm{r}}=475}=0.71 \mathrm{~g} \ldots \ldots \mathrm{Sa}(\mathrm{T}=0.3 \mathrm{~s})_{T_{\mathrm{r}}=50}=0.29 \mathrm{~g}$

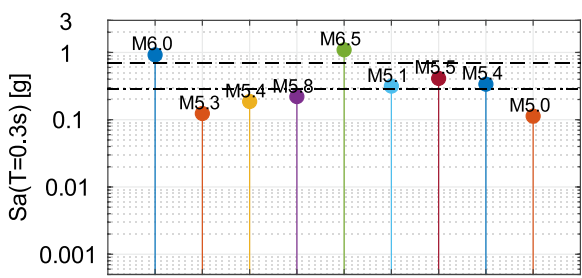

$-\ldots . \mathrm{Sa}(\mathrm{T}=3 \mathrm{~s})_{\mathrm{T}_{\mathrm{r}}=475}=0.10 \mathrm{~g} \ldots \ldots \mathrm{Sa}(\mathrm{T}=3 \mathrm{~s})_{\mathrm{T}_{\mathrm{r}}=50}=0.03 \mathrm{~g}$

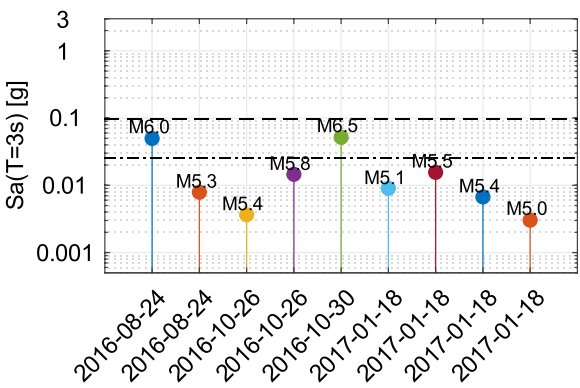

Fig. 10 Ground motion intensity, in terms of PGA, $S a(T=0.3 \mathrm{~s}), S a(T=1 \mathrm{~s})$ and $S a(T=3 \mathrm{~s})$, for Amatrice according to ShakeMap for each of the M5+earthquakes of the sequence

The case of Visso, represented in Fig. 12, is also interesting: in the afternoon of October 26th a M5.4 event occurred in proximity of the site, and a closer event with M5.8 occurred two hours later. Looking at the low vibration periods, it can be observed that accelerations provided by the ShakeMap for the two earthquakes are comparable for both PGA and $S a(T=0.3 \mathrm{~s})$. Owing to the low epicentral distances (i.e., $3 \mathrm{~km}$ for M5.8 and $7 \mathrm{~km}$ for M5.4) and to the earthquake features, ground-shaking in terms of PGA and $S a(T=0.3 \mathrm{~s})$ was larger than that recorded due to the farthermost M6.0, about $30 \mathrm{~km}$ away from the site, and-only slightly - smaller than the accelerations pertaining to the M6.5 event, which occurred $11 \mathrm{~km}$ away from Visso. In the case of $S a(T=1 \mathrm{~s})$, shock intensity due to M6.0 remains lower than that for M5.8, but it is larger than the acceleration estimated for M5.4. As it pertains to $S a(T=3 \mathrm{~s})$, ShakeMap for M6.0 and M5.8 provides an almost equal shaking, which is in turn slightly smaller than that for M6.5. Thus, despite the relatively moderate events magnitude, two exceedances of the PGA from the code spectrum with $T_{r}=475 \mathrm{yr}$ were estimated at Visso on October 26th, and an additional exceedance occurred on October 30th. With reference to $S a(T=0.3 \mathrm{~s})$, the only exceedance of the sequence is because of the mainshock, even if accelerations due to M5.4 and M5.8 are actually almost equal to the threshold from the code spectrum. Looking at $S a(T=1 \mathrm{~s})$ and $S a(T=3 \mathrm{~s})$ spectral ordinates, the mainshock intensity is smaller than the design spectral ordinates with $T_{r}=475 \mathrm{yr}$, and therefore no exceedance is found at the site.

If ground motions from ShakeMap are compared to the code spectrum with $T_{r}=50 \mathrm{yr}$, one note that, considering PGA, $S a(T=0.3 \mathrm{~s})$ and $S a(T=1 \mathrm{~s})$, the number 
Norcia

$-\ldots-. P \mathrm{PA}_{\mathrm{T}_{\mathrm{r}}=475}=0.34 \mathrm{~g} \ldots \ldots \mathrm{PGA}_{\mathrm{T}_{\mathrm{r}}=50}=0.15 \mathrm{~g}$

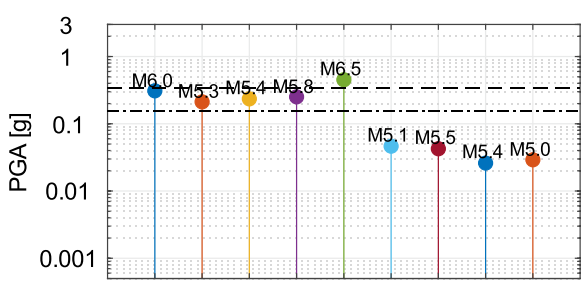

$-\ldots . . \mathrm{Sa}(\mathrm{T}=1 \mathrm{~s})_{\mathrm{T}_{\mathrm{r}}=475}=0.41 \mathrm{~g} \ldots \ldots . . . \mathrm{Sa}(\mathrm{T}=1 \mathrm{~s})_{\mathrm{T}_{\mathrm{r}}=50}=0.16 \mathrm{~g}$

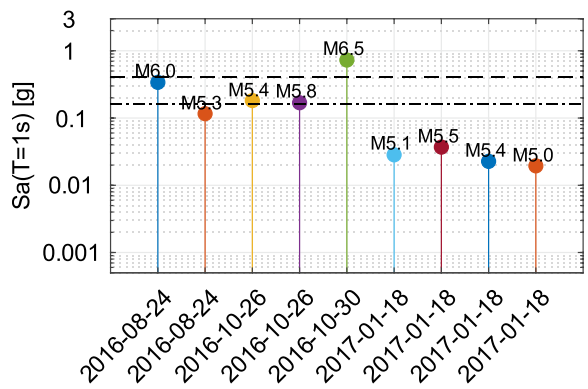

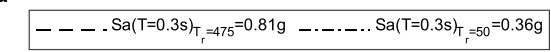

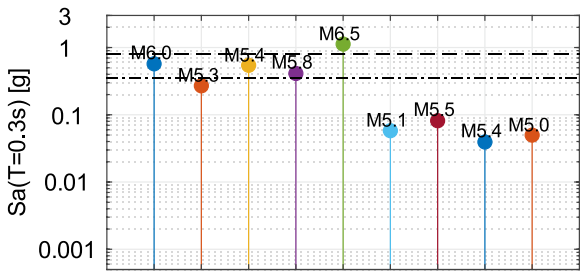

$-\ldots . \mathrm{Sa}(\mathrm{T}=3 \mathrm{~s})_{T_{\mathrm{r}}=475}=0.12 \mathrm{~g} \ldots \ldots \mathrm{Sa}(\mathrm{T}=3 \mathrm{~s})_{\mathrm{T}_{\mathrm{r}}=50}=0.04 \mathrm{~g}$

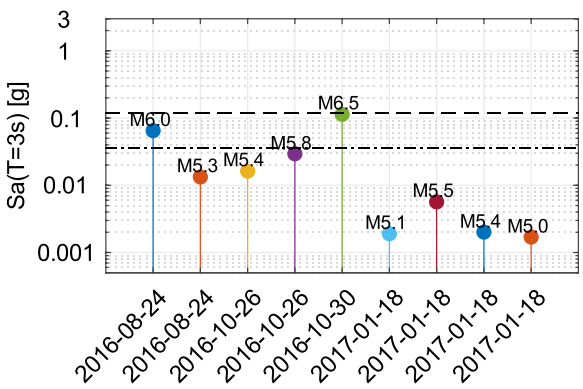

Fig. 11 Ground motion intensity, in terms of PGA, $S a(T=0.3 \mathrm{~s}), S a(T=1 \mathrm{~s})$ and $S a(T=3 \mathrm{~s})$, for Norcia according to each of the M5+ earthquakes of the sequence

of earthquakes of the sequence causing exceedance is larger than those causing nonexceedance in the case of Amatrice (Fig. 10) and Norcia (Fig. 11), whereas exceedance at Accumoli and Visso was estimated to have occurred in four out of nine events, as shown in Figs. 9 and 12, respectively. The number of exceedances at each site in the case of $\operatorname{Sa}(T=3 \mathrm{~s})$ is lower, being three at Visso and two at the others. Due to the significant reduction of the design spectral accelerations for this return period, the two largest magnitude events of the sequence might have caused exceedance at all sites, regardless of the epicentral distance. Moreover, looking at the four earthquakes occurred on January 18th, each characterized by a relatively moderate magnitude, it can be observed that they should not have caused exceedance of any spectral ordinate at the furthermost sites, that is, Norcia and Visso. In fact, among these events, those with M5.1, M5.4 and M5.5 caused exceedance of one between code-mandated PGA and $S a(T=0.3 \mathrm{~s})$ at the site closest to the epicenters, that is, Amatrice. On the other hand, exceedance at Accumoli was only observed in the case of PGA due to the M5.5 earthquake. Finally, despite the low return period, the smallest magnitude event (M5.0) did not cause exceedance of any spectral ordinate at each of the considered sites. 

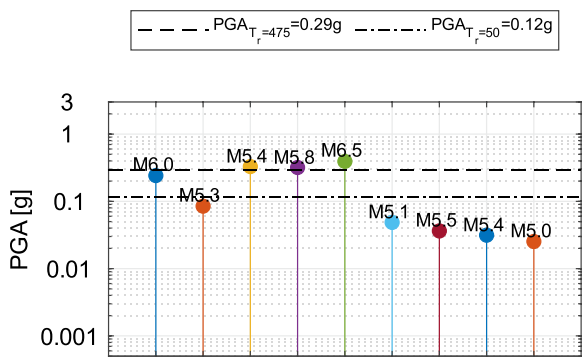

$--. . \mathrm{Sa}(\mathrm{T}=1 \mathrm{~s})_{\mathrm{T}_{\mathrm{r}}=475}=0.31 \mathrm{~g} \ldots \ldots . . . \mathrm{Sa}(\mathrm{T}=1 \mathrm{~s})_{\mathrm{T}_{\mathrm{r}}=50}=0.11 \mathrm{~g}$

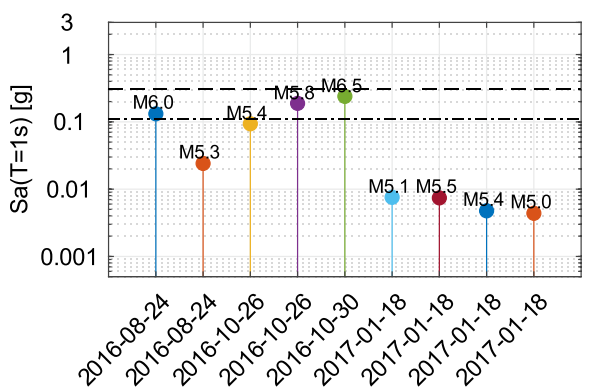

Visso

$-\ldots-. \mathrm{Sa}(\mathrm{T}=0.3 \mathrm{~s})_{\mathrm{T}_{\mathrm{f}}=475}=0.68 \mathrm{~g} \ldots \ldots \mathrm{Sa}\left(\mathrm{T}=0.3 \mathrm{~s}_{\mathrm{T}_{\mathrm{r}}=50}=0.28 \mathrm{~g}\right.$

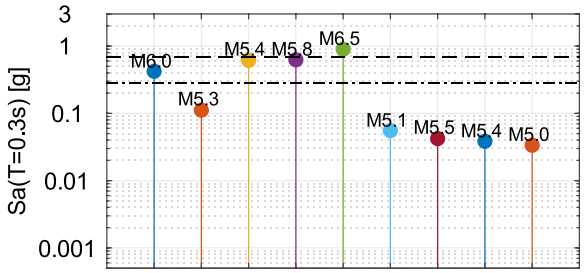

$-\ldots . \mathrm{Sa}(\mathrm{T}=3 \mathrm{~s})_{\mathrm{T}_{\mathrm{r}}=475}=0.09 \mathrm{~g} \ldots \ldots \mathrm{Sa}(\mathrm{T}=3 \mathrm{~s})_{\mathrm{T}_{\mathrm{r}}=50}=0.02 \mathrm{~g}$

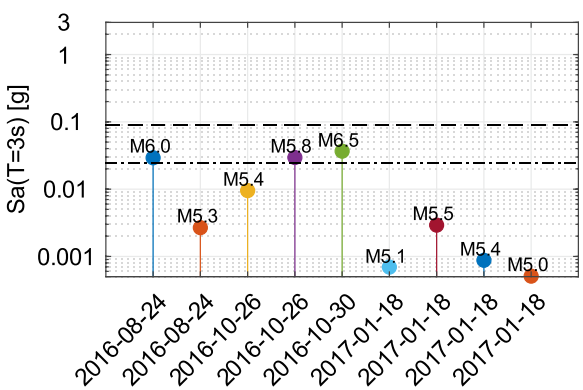

Fig. 12 Ground motion intensity, in terms of PGA, $S a(T=0.3 \mathrm{~s}), S a(T=1 \mathrm{~s})$ and $S a(T=3 \mathrm{~s})$, for Visso according to ShakeMap for each of the M5+earthquakes of the sequence

Fig. 13 Epicentral distances for the M5+earthquakes for Accumoli, Amatrice, Norcia and Visso

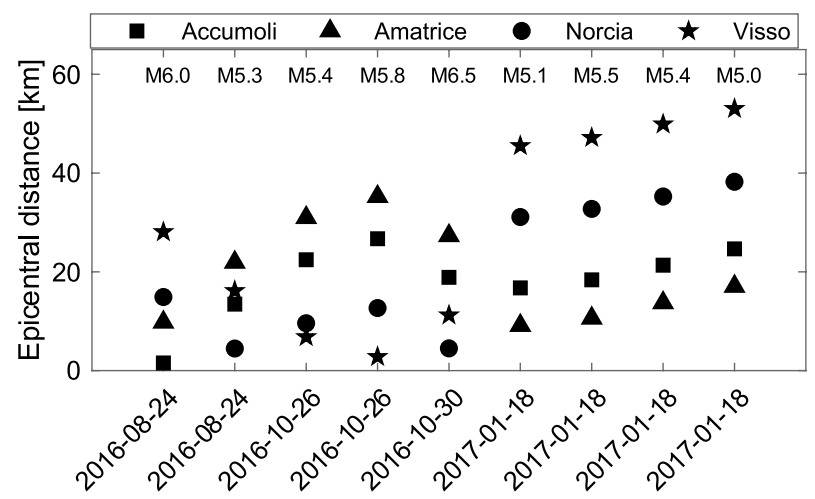

\section{Conclusions}

Between August 2016 and January 2017, seven earthquakes with magnitude ranging from 5.0 to 5.8 and two with magnitude equal to 6.0 and 6.5 occurred in a relatively small region surrounding the villages of Accumoli, Amatrice, Norcia and Visso, that is, the 2016-2017 central Italy seismic sequence. In the cases of long-lasting seismic sequences, as this one, ShakeMap envelopes can be useful to estimate the portion of the building heritage exposed to the most relevant seismic actions. In the simple study presented, the 
ShakeMap envelopes for the M5+ earthquakes, in terms of PGA, $\operatorname{Sa}(T=0.3 \mathrm{~s}), \operatorname{Sa}(T=1 \mathrm{~s})$ and $S a(T=3 \mathrm{~s})$, were analyzed, also in comparison with those specific for the two largest events of the sequence; i.e., the initiating M6.0 and the M6.5 mainshock. Considering two exceedance return periods of interest for structural design, ground motion intensities from the ShakeMap were compared to the probabilistic-hazard-based design actions mandated by the current Italian building code. This allowed to estimate the size of the near-sourcearea of the events where exceedance of design seismic actions for new constructions was observed. Finally, with reference to four sites, the intensity-history that buildings have been subjected to in a relatively short period of time (i.e., a few months) has been discussed.

The following conclusions are worth recalling.

- A wide region of central Italy is expected to have experienced spectral accelerations even larger than half of the maximum recorded during the whole sequence. Such an area covers about $900 \mathrm{~km}^{2}$ for both PGA and $\operatorname{Sa}(T=0.3 \mathrm{~s})$, whereas it is between 400 and $500 \mathrm{~km}^{2}$ for $S a(T=1 \mathrm{~s})$ and $S a(T=3 \mathrm{~s})$.

- The comparison between the ShakeMap envelopes and those for the M6.5 earthquake revealed that the largest shaking of the sequence are mostly attributable to the mainshock. However, there are also relatively small areas where the largest ground motion intensity is attributable by other events of the sequence, which points to the usefulness of ShakeMap envelopes for seismic sequences.

- According to data that ShakeMap for each event is based on, envelopes reveal that at least one exceedance of the design seismic actions enforced by the current building code was observed between August 2016 and January 2017 in a large area. It was herein quantified in $2600-5500 \mathrm{~km}^{2}$ (depending on the spectral ordinate), when considering $T_{r}=50 \mathrm{yr}$. The exceedance area reduces to $80-1300 \mathrm{~km}^{2}$, when referring to $T_{r}=475 \mathrm{yr}$. Several M5+events of the sequence also caused systematic exceedances around their epicentres. However, the assessment of the areas exposed to at least one exceedance is affected by ShakeMap estimation uncertainty, considering which it was found that exceedance area of code-mandated seismic action can be estimated within the range $10,000-20,000 \mathrm{~km}^{2}$ in the case of $T_{r}=50 \mathrm{yr}$ (depending on the spectral ordinate) and $1000-3000 \mathrm{~km}^{2}$ in the case of $T_{r}=475 \mathrm{yr}$.

- In the case of mainshocks, the total exceedance area over the country is expected, in fifty years, to add-up to ten and sixty-three percent for $T_{r}=475 \mathrm{yr}$ and $T_{r}=50 \mathrm{yr}$, respectively. For the mainshock of the central Italy sequence and with reference to PGA, $S a(T=0.3 \mathrm{~s})$ and $S a(T=1 \mathrm{~s})$, such percentages were in the ranges $0.19-0.40 \%$ and $0.57-1.49 \%$ for $T_{r}=475 \mathrm{yr}$ and $T_{r}=50 \mathrm{yr}$, respectively. Exceedance of the $S a(T=3 \mathrm{~s})$ of the code spectrum with $T_{r}=50 \mathrm{yr}$ and $T_{r}=475 \mathrm{yr}$ was found in an area covering about $1.49 \%$ and $0.03 \%$ of Italy, respectively.

- Several sites in the region might have experienced multiple exceedances of the design ground motion in a short time, pointing to the relevance of the seismic damage accumulation issues. In fact, the PGA of the code spectrum with $T_{r}=475 \mathrm{yr}$ was exceeded once at Norcia, twice at Accumoli and Amatrice, and three times at Visso. The $S a(T=0.3 \mathrm{~s})$ spectral ordinate was exceeded twice Amatrice, and once at Accumoli, Norcia and Visso. With reference to $S a(T=1 \mathrm{~s})$, only one exceedance was estimated at Accumoli and Norcia, whereas in the case of $S a(T=3 \mathrm{~s})$, none among the considered sites experience exceedance. As it pertains to $T_{r}=50 \mathrm{yr}$, the number of the M5+earthquakes of the sequence causing exceedance was five in the case of Amatrice and Norcia, while four exceedances were estimated at Accumoli and Visso, considering 
PGA, $S a(T=0.3 \mathrm{~s})$ and $S a(T=1 \mathrm{~s})$ In the case of $S a(T=3 \mathrm{~s})$, three exceedance were estimated at Visso and two at the other sites.

Acknowledgements Authors are grateful to the anonymous reviewer for the helpful comments which helped in improving the quality of the manuscript. The commissariat for the reconstruction in the area hit by the central Italy sequence is also acknowledged to having sparked this study.

Funding Open access funding provided by Università degli Studi di Napoli Federico II within the CRUICARE Agreement. The study presented in this article was developed within the activities of the ReLUISDPC 2019-20121 research program, funded by Presidenza del Consiglio dei Ministri - Dipartimento della Protezione Civile (DPC).

Data Availability Shaking intensities from ShakeMap envelopes and seismic hazard data (considering local site conditions) for the comparisons shown in the study, are available at http://wpage.unina.it/iuniervo/ papers/ShakeMap_envelopes_and_hazard.xlsx. Code availability: all ShakeMap data were retrieved from http://ShakeMap.rm.ingv.it/; last accessed June 2021).

\section{Declarations}

Conflict of interest The authors declare that they have no conflict of interest.

Open Access This article is licensed under a Creative Commons Attribution 4.0 International License, which permits use, sharing, adaptation, distribution and reproduction in any medium or format, as long as you give appropriate credit to the original author(s) and the source, provide a link to the Creative Commons licence, and indicate if changes were made. The images or other third party material in this article are included in the article's Creative Commons licence, unless indicated otherwise in a credit line to the material. If material is not included in the article's Creative Commons licence and your intended use is not permitted by statutory regulation or exceeds the permitted use, you will need to obtain permission directly from the copyright holder. To view a copy of this licence, visit http://creativecommons.org/licenses/by/4.0/.

\section{References}

Buratti N, Minghini F, Ongaretto E et al (2017) Empirical seismic fragility for the precast RC industrial buildings damaged by the 2012 Emilia (Italy) earthquakes. Earthq Eng Struct Dyn 46:2317-2335. https://doi.org/10.1002/eqe.2906

C.S.LL.PP. (2018) Decreto Ministeriale: Norme tecniche per le costruzioni, Gazzetta Ufficiale della Repubblica Italiana, n. 42, 20 febbraio, Suppl. Ordinario n. 8. Ist. Polig. e Zecca dello Stato S.p.a., Rome (in Italian)

Chioccarelli E, Iervolino I (2010) Near-source seismic demand and pulse-like records: a discussion for L'Aquila earthquake. 39:1039-1062. https://doi.org/10.1002/eqe.987

Cito P, Iervolino I (2020) Rarity, proximity, and design actions: mapping strong earthquakes in Italy. Ann Geophys 63:SE671. https://doi.org/10.4401/ag-8516

Forte G, Chioccarelli E, De Falco M et al (2019) Seismic soil classification of Italy based on surface geology and shear-wave velocity measurements. Soil Dyn Earthq Eng 122:79-93. https://doi.org/10.1016/j. soildyn.2019.04.002

Iervolino I (2013) Probabilities and fallacies: why hazard maps cannot be validated by individual earthquakes. Earthq Spectra 29:1125-1136. https://doi.org/10.1193/1.4000152

Iervolino I, Chioccarelli E, Convertito V (2011) Engineering design earthquakes from multimodal hazard disaggregation. Soil Dyn Earthq Eng 31:1212-1231. https://doi.org/10.1016/j.soildyn.2011.05.001

Iervolino I, De Luca F, Chioccarelli E (2012) Engineering seismic demand in the 2012 Emilia sequence: preliminary analysis and model compatibility assessment. Ann Geophys 55:639-645. https://doi.org/ 10.4401/ag-6118

Iervolino I, Baltzopoulos G, Chioccarelli E, Suzuki A (2019a) Seismic actions on structures in the nearsource region of the 2016 central Italy sequence. Bull Earthq Eng 17:5429-5447. https://doi.org/10. $1007 / \mathrm{s} 10518-017-0295-3$ 
Iervolino I, Giorgio M, Cito P (2019b) Which earthquakes are expected to exceed the design spectra? Earthq Spectra. https://doi.org/10.1193/032318EQS066O

Luzi L, Pacor F, Puglia R et al (2017) The central italy seismic sequence between August and December 2016: analysis of strong-motion observations. Seismol Res Lett 88:1219-1231. https://doi.org/10. $1785 / 0220170037$

Michelini A, Faenza L, Lanzano G et al (2019) The new shakemap in Italy: progress and advances in the last 10 yr. Seismol Res Lett 91:317-333. https://doi.org/10.1785/0220190130

Moretti M, Pondrelli S, Margheriti L et al (2016) SISMIKO: Emergency network deployment and data sharing for the 2016 central Italy seismic sequence. Ann Geophys. https://doi.org/10.4401/ag-7212

Stucchi M, Meletti C, Montaldo V et al (2011) Seismic hazard assessment (2003-2009) for the Italian building code. Bull Seismol Soc Am 101:1885-1911. https://doi.org/10.1785/0120100130

Suzuki A, Iervolino I (2017) Italian versus worldwide history of largest PGA and PGV. Ann Geophys 60:S0551

Wald DJ, Quitoriano V, Heaton TH et al (1999) TriNet "ShakeMaps": rapid generation of peak ground motion and intensity maps for earthquakes in Southern California. Earthq Spectra 15:537-555. https:// doi.org/10.1193/1.1586057

Worden CB, Thompson EM, Baker JW et al (2018) Spatial and spectral interpolation of ground-motion intensity measure observationsspatial and spectral interpolation of ground-motion intensity measure observations. Bull Seismol Soc Am 108:866-875. https://doi.org/10.1785/0120170201

Publisher's Note Springer Nature remains neutral with regard to jurisdictional claims in published maps and institutional affiliations. 